\title{
REVIEW
}

\section{Oseltamivir in Seasonal, Pandemic, and Avian Influenza: a Comprehensive Review of 10-Years Clinical Experience}

James R. Smith · Craig R. Rayner · Barbara Donner · Martina Wollenhaupt · Klaus Klumpp · Regina Dutkowski

Received: August 8, 2011 / Published online: November 1, 2011

(c) The Author(s) 2011. This article is published with open access at Springerlink.com

\section{ABSTRACT}

Oseltamivir (Tamiflu ${ }^{\circledR}$; F. Hoffmann-La Roche Ltd, Basel, Switzerland) is an orally administered antiviral for the treatment and prevention of influenza A and B infections that is registered in more than 100 countries worldwide. More than 83 million patients have been exposed to the product since its introduction. Oseltamivir is recommended by the World Health Organization (WHO) for use in the clinical management of pandemic and seasonal influenza of varying severity, and as the primary antiviral agent for treatment of avian H5N1 influenza infection in humans. This article is a nonsystematic review of the experience gained from the first 10 years of using oseltamivir for

James R. Smith $(\varangle) \cdot$ Barbara Donner · Martina Wollenhaupt

F. Hoffmann-La Roche Ltd, Pharmaceuticals Division, PBMT Bldg 74/3O Z1.06, CH-4070, Basel, Switzerland.

Email: james.smith.js1@roche.com

Craig R. Rayner

Roche Products Pty Ltd, Melbourne, Australia and Faculty of Pharmacy and Pharmaceutical Sciences,

Monash University, Melbourne, Australia

Klaus Klumpp · Regina Dutkowski

Hoffmann-La Roche, Inc., Nutley, NJ, US influenza infections since its launch in early 2000, emphasizing recent advances in our understanding of the product and its clinical utility in five main areas. The article reviews the pharmacokinetics of oseltamivir and its active metabolite, oseltamivir carboxylate, including information on special populations such as children and elderly adults, and the co-administration of oseltamivir with other agents. This is followed by a summary of data on the effectiveness of oseltamivir treatment and prophylaxis in patients with all types of influenza, including pandemic (H1N1) 2009 and avian H5N1 influenza. The implications of changes in susceptibility of circulating influenza viruses to oseltamivir and other antiviral agents are also described, as is the emergence of antiviral resistance during and after the 2009 pandemic. The fourth main section deals with the safety profile of oseltamivir in standard and special patient populations, and reviews spontaneously reported adverse event data from the pandemic and pre-pandemic periods and the topical issue of neuropsychiatric adverse events. Finally, the article considers the pharmacoeconomics of oseltamivir in comparison with vaccination and usual care regimens, and as a component of pandemic influenza mitigation strategies. 
Keywords: avian; efficacy; influenza; oseltamivir; pandemic; pharmacoeconomics; pharmacokinetics; resistance; safety; seasonal

\section{INTRODUCTION}

Although the 2009-2010 pandemic outbreak raised public awareness of the serious threats posed by influenza infections, the burden of seasonal influenza infections is probably still under-appreciated. It is estimated, for example, that up to $20 \%$ of people in the United States (US) develop influenza each season, and that between 3000-49,000 of those infections will be fatal, while nearly a quarter of a million influenza patients will require hospitalization..$^{1-3}$ During influenza pandemics, the disease burden changes with respect to the age group affected. Children and younger adults, who are proportionally less affected by seasonal influenza epidemics, bore the brunt of serious illness and mortality during the 2009-2010 H1N1 pandemic, ${ }^{4}$ because they had little or no existing immunity to the novel virus. Human cases of avian H5N1 influenza, which have occurred geographically from South-East Asia to the Middle East and Africa, are associated with much poorer outcomes than seasonal illness, typically causing severe illness which proves fatal in nearly $60 \%$ of confirmed cases. ${ }^{5}$
Oseltamivir (Tamiflu ${ }^{\circledR}$; F. Hoffmann-La Roche Ltd, Basel, Switzerland) is an orally administered antiviral for the treatment and prevention of influenza A and B infections. In adults, it is administered as a $75 \mathrm{mg}$ oral capsule, but small oral capsules (30 mg and $45 \mathrm{mg}$ ) and oral suspension formulations are also available for use in younger children and renally impaired patients. A solution form can also be prepared if necessary from the contents of an opened capsule (extemporaneous compounding). ${ }^{6,7}$ Recommended dosages are shown in Table 1. For seasonal influenza, oseltamivir is indicated for children $\geq 1$ year old and adults of all ages, and dosing recommendations for infants $<1$ year old infected with pandemic influenza are also provided. ${ }^{6}$ Oseltamivir is an inactive prodrug: its clinically active metabolite is oseltamivir carboxylate (OC). In infected individuals, OC selectively binds to and inhibits the conserved active site of the neuraminidase enzymes that are present as major surface antigens on all types of influenza viruses. As neuraminidase is essential for the release of progeny virions from infected cells, ${ }^{8}$ inhibiting this enzyme limits the duration and severity of the infection.

The World Health Organization (WHO) revised its guidance on pharmacological management of seasonal and pandemic

Table 1. Recommended oseltamivir dosages for the treatment and prevention of seasonal and pandemic influenza infections in children, adolescents, and adults.

\begin{tabular}{lccc}
\hline & & Treatment & Post-exposure prophylaxis \\
\cline { 3 - 4 } Age group & Body weight $(\mathbf{k g})$ & 5-day course (twice daily) & 10-day course (once daily) \\
\hline Adults; adolescents aged & - & $75 \mathrm{mg}$ & $75 \mathrm{mg}$ \\
$\geq 13$ years & $>40$ & $75 \mathrm{mg}$ & $75 \mathrm{mg}$ \\
\hline Children aged 1-12 years & $>23-40$ & $60 \mathrm{mg}$ & $60 \mathrm{mg}$ \\
& $>15-23$ & $45 \mathrm{mg}$ & $45 \mathrm{mg}$ \\
& $\leq 15$ & $30 \mathrm{mg}$ & $30 \mathrm{mg}$ \\
\hline
\end{tabular}


influenza in August 2009 in response to the developing global influenza pandemic, and these guidelines were further revised and simplified in February 2010.9 The updated version harmonized recommendations with respect to antiviral therapies, giving the same advice for infection with pandemic viruses as for infection with seasonal viruses. For influenza with an uncomplicated clinical presentation, prompt treatment with neuraminidase inhibitors is recommended if patients are at elevated risk of severe or complicated disease, including infants (particularly those aged $<2$ years), pregnant women, those with chronic respiratory, cardiac, or metabolic disorders, and those aged $\geq 65$ years. For severe or progressive influenza, WHO recommends oseltamivir treatment for all patients; for immunosuppressed patients, WHO advice is to consider using the drug at higher doses and/or longer treatment duration, depending on clinical response; ${ }^{9}$ however, UK national guidelines recommend zanamivir. ${ }^{10}$ For treatment of influenza caused by viruses known to be resistant to oseltamivir, WHO recommends zanamivir. ${ }^{9}$ Earlier WHO guidelines also recommend oseltamivir as the primary antiviral agent for treatment of confirmed and suspected cases of avian H5N1 influenza infection in humans; treatment should begin as soon as possible, but can be beneficial even in patients who present later in the disease course. ${ }^{11,12}$ Again, consideration should be given to higher doses and/or longer treatment duration, depending on the clinical course of disease.

Following its first regulatory approval in Switzerland in 1999, oseltamivir is now registered in more than 100 countries worldwide as of February 2011, with more than 83 million patients having been exposed to the product since its introduction. This article is a nonsystematic review of some of the experience gained from the first 10 years of using oseltamivir in the clinical management of influenza infections, focusing on the product's efficacy and safety and the effect of emerging resistance to oseltamivir and other antivirals. Sections are also included on the pharmacology of oseltamivir and pharmacoeconomic evaluations.

\section{PHARMACODYNAMICS AND PHARMACOKINETICS}

\section{Pharmacodynamics}

As already described, oseltamivir prevents the release of progeny virions from cells infected by influenza viruses, through inhibition of viral neuraminidase by its active metabolite, OC. In humans, the standard oseltamivir dosing regimen produces a mean minimum plasma concentration of the carboxylate metabolite of approximately $330 \mathrm{nmol} / \mathrm{L} .{ }^{13}$ The majority of virus isolates from all influenza $A$ and B subtypes tested thus far are susceptible, including seasonal, avian, and pandemic (H1N1) 2009 viruses. ${ }^{14-16}$

\section{Pharmacokinetics}

\section{Oseltamivir and $O C$}

Many of the key pharmacokinetic characteristics of oseltamivir and OC in humans were reported in the 1999 article by $\mathrm{He}$ and colleagues. ${ }^{13}$ More recently, a better understanding of the pharmacokinetics in special populations has been gained.

Oseltamivir is readily absorbed from the gastrointestinal tract after oral administration - it readily enters hepatocytes, where it is extensively converted ( $>90 \%)$ to the active metabolite, OC, by hepatic carboxylesterases, particularly human carboxylesterase-1 (HCE-1). The efflux of OC from hepatocytes is permeability-limited. No other metabolites have been described in humans. 
Maximal concentrations of OC occur at approximately 3-4 hours. Plasma concentrations of OC are unaffected by co-administration with food, and at least $75 \%$ of an oral dose of oseltamivir reaches the systemic circulation as the active metabolite. Once in plasma, OC distributes to typical sites of viral infection in the upper and lower respiratory tract, ${ }^{13,17}$ and neither oseltamivir nor OC appear to penetrate the central nervous system (CNS) to any appreciable extent. ${ }^{18}$ Binding to plasma proteins is low ( $42 \%$ for oseltamivir and $<3 \%$ for OC). OC and any remaining small amounts of oseltamivir yet to be converted to $\mathrm{OC}$ are eliminated unchanged in the urine via glomerular filtration and tubular secretion (the latter via organic anion transporter [OAT-1]). The plasma half-life of OC is 6-10 hours, which enables a twice-daily dosing regimen.

Intra- and inter-subject variability in plasma concentrations of oseltamivir and OC are low and the pharmacokinetics of both after single doses display linear kinetics at doses of up to $500 \mathrm{mg}$ twice daily. Steady-state plasma concentrations of OC occur within 3 days of twice-daily dosing, with minimal accumulation of oseltamivir and less than two-fold accumulation of OC.

During the development programme, both oseltamivir and OC were administered intravenously (i.v.) to fully characterize individual pharmacokinetics in humans. After i.v. OC administration, the half-life of OC is only 1-2 hours, whereas after i.v. oseltamivir administration, the half-life of OC is comparable to that obtained following oral oseltamivir dosing. These findings are consistent with the need to deliver oseltamivir to hepatocytes, as the permeability-limited release of OC from these cells enables twice-daily dosing. An i.v. formulation of oseltamivir is in clinical development and was used during the 2009-2010 pandemic outbreak in Europe and Australia, under compassionate use arrangements (see SAFETY section; Intravenous Administration).

\section{Special Patient Populations}

The pharmacokinetics of oseltamivir after oral administration have been studied in young, healthy adults and children, as well as in elderly and very elderly subjects. ${ }^{19-21}$ There are no clinically relevant differences between pharmacokinetics in healthy volunteers and individuals with influenza. ${ }^{13}$

The main difference between children $>1$ year of age and adults in oseltamivir pharmacokinetics is that children aged 1-12 years clear the active metabolite more rapidly than adults, resulting in a lower drug exposure for a given dose; however, the exposureto-dose ratio in older children (adolescents) aged 13-18 years is similar to that in adults. ${ }^{21}$ The higher clearance rate prompted the introduction of an age- and weight-based unit dosing system for children, to ensure comparable exposures to those in adults and to enable drug exposure in children to be maintained within a target efficacy/safety window. ${ }^{21}$

In infants, other considerations when identifying a dose range for oseltamivir are the rapid development of renal function and transporter function that occur early in life, as well as the potential for a lower level of metabolic activity. ${ }^{22,23}$ Clinical studies to determine the appropriate dosage in infants aged $<1$ year are progressing. Interim results from one exposure-targeted study suggest that the appropriate oseltamivir doses for twice-daily administration are $3.0 \mathrm{mg} / \mathrm{kg}$ from $0-8$ months of age, and $3.5 \mathrm{mg} / \mathrm{kg}$ from 9-11 months of age. ${ }^{24}$ Another study in influenza-infected infants (ClinicalTrials.gov identifier: NCT00988325) is exploring the suitability of slightly lower dosage regimens, ie, $2 \mathrm{mg} / \mathrm{kg}$ for neonates up to 1 month old, 
$2.5 \mathrm{mg} / \mathrm{kg}$ for those aged 1-3 months, and $3 \mathrm{mg} / \mathrm{kg}$ for those aged 3 months to 1 year, all given twice daily. Provisional pooled pharmacokinetic data suggest that lower body-weight adjusted doses may be needed in premature babies (eg, $1.0 \mathrm{mg} / \mathrm{kg}$ twice daily), ${ }^{25}$ although additional data are needed to establish a dosing recommendation.

In elderly patients, the exposure-to-dose ratio for OC increases, because of age-related decline in renal function, but this increase is small, relative to the drug's known safety margin, and no dose adjustment is required. ${ }^{19}$ Pharmacokinetics have not yet been investigated in detail in pregnant and lactating women, but this is the subject of study in current clinical trials (ClinicalTrials.gov identifiers: NCT01203527 and NCT01130636). It has been shown in an ex vivo human placenta model that trans-placental transfer of oseltamivir and its active metabolite is undetectable at normal therapeutic doses. ${ }^{26}$ In lactating rats, oseltamivir and OC are excreted in milk. ${ }^{6,7}$ Information on lactating women is very limited. In a single case report, oseltamivir and its carboxylate were detected in breast milk collected over 5 consecutive days of treatment (75 mg twice-daily dose). Concentrations were low and were considered unlikely to have any therapeutic significance in the suckling infant. ${ }^{27}$

As expected for a renally excreted drug, exposure to $\mathrm{OC}$ increases when renal function is impaired, and because patients with severe renal insufficiency (creatinine clearance rates of $\leq 30 \mathrm{~mL} / \mathrm{min}$ ) have higher drug exposures than those with normal renal function, ${ }^{13}$ lower doses are recommended in such patients. ${ }^{6}$ The $30 \mathrm{mg}$ capsule formulation facilitates dosing in patients with severe renal impairment: specifically, the recommended dosages in patients with creatinine clearance of $10-30 \mathrm{~mL} / \mathrm{min}$ are $75 \mathrm{mg}$ once daily (or $30 \mathrm{mg}$ twice daily) for treatment, and $75 \mathrm{mg}$ once every other day (or $30 \mathrm{mg}$ once daily) for prophylaxis. No dose adjustment is necessary for patients with creatinine clearance of $>30 \mathrm{~mL} / \mathrm{min}$. Oseltamivir is not recommended for patients with end-stage renal disease (creatinine clearance $<10 \mathrm{~mL} / \mathrm{min}$ ), although a modified oral dosage regimen was shown to be well tolerated in hemodialysis (HD) and continuous ambulatory peritoneal dialysis (CAPD) patients. ${ }^{28}$ Based on modeling and simulation data (Roche, data on file), patients undergoing routine HD who develop influenza symptoms in the 48 hours between dialysis sessions could be given a $30 \mathrm{mg}$ dose before dialysis and a $30 \mathrm{mg}$ dose after each dialysis session. The oseltamivir dosage does not need adjustment in patients with mild to moderate hepatic impairment. ${ }^{29}$ Oseltamivir has not been evaluated in patients with severe hepatic impairment.

Currently, there are no data to support a need for changing oseltamivir dosing on the basis of ethnopharmacology or genetic polymorphisms. No clinically relevant differences have been seen in plasma or cerebrospinal fluid (CSF) pharmacokinetics between Japanese and Caucasian individuals. ${ }^{18,20}$ Polymorphisms affecting the transporter OAT-1 have been reported, but are of low functional significance, and although HCE-1 alleles with altered in vitro functional properties have been described, there is no evidence that HCE-1 polymorphisms result in clinically relevant changes in the conversion rate of oseltamivir to OC in humans.

\section{Co-administration with Other Agents}

Oseltamivir has limited potential for clinically relevant interactions with other drugs commonly administered to influenza patients. When oseltamivir was given with amantadine, rimantadine, paracetamol, aspirin, antacids, cimetidine, amoxicillin, or warfarin, no changes 
occurred in the systemic exposure of oseltamivir or the co-administered drug. ${ }^{13,30-35}$ Similarly, no pharmacokinetic interaction was noted with the immunosuppressant drugs cyclosporine, mycophenolate mofetil, or tacrolimus in renal transplant patients. ${ }^{36}$ Probenecid, however, inhibits tubular secretion of oseltamivir, thus increasing the latter's systemic exposure. ${ }^{34}$ The potential for this particular interaction to allow drug-sparing, ie, reducing the oseltamivir dose without compromising efficacy, has been explored in more recent studies, ${ }^{37,38}$ but because of concerns about unreliable efficacy, and a possible increase in risk of antiviral resistance, such a combination is not recommended.

\section{EFFICACY}

\section{Seasonal Influenza}

\section{Adults}

The inhibition of influenza virus replication by oseltamivir, as described in the previous section, significantly shortens the course of illness and reduces disease severity. The first demonstrations of these treatment benefits in clinical practice were in patients with seasonal influenza. The outcomes of large, randomized, controlled trials published in 2000, just after oseltamivir was first introduced, showed that a dose of $75 \mathrm{mg}$ given twice daily for 5 days reduced illness duration and symptom severity in adults aged 18-65 years with influenza A and B infections. ${ }^{39,40}$ The study by Treanor et al. ${ }^{39}$ also showed that treatment reduced the incidence of secondary complications and the need for antibiotics in adults; benefits which were also demonstrated when data from the Treanor and Nicholson ${ }^{40}$ trials were pooled with data from eight other studies in adults, adolescents, and elderly adults (>65 years old); ${ }^{41}$ this pooled analysis also demonstrated a reduced risk of hospitalization.
With respect to the prevention of seasonal influenza, efficacy of oseltamivir was demonstrated both as post-exposure prophylaxis (PEP; $75 \mathrm{mg}$ once daily for 7 or 10 days) and seasonal prophylaxis (a 6-week course at the same dosage). In the PEP setting, significant reductions in the incidence of clinical illness were reported both in a study of household contacts (adults and adolescents) of untreated index cases with influenza-like illness (ILI), ie, a reduction of $89 \%(P<0.001),{ }^{42}$ and a study of 138 households where index cases with ILI were treated, in which the protective efficacy against confirmed influenza in adults and children was $58.5 \%(P<0.05) .{ }^{43}$ Seasonal prophylaxis with $75 \mathrm{mg}$ oseltamivir once daily for 6 weeks reduced the incidence of clinical illness in adults by $76 \%(P<0.001)^{44}$ and in elderly residents of nursing homes by $92 \%(P<0.01) .{ }^{45}$

\section{Children}

Treatment with oseltamivir produces a similar range of benefits in children aged 1-12 years, including a reduction, relative to placebo, in the duration of fever and in the number of secondary infections, notably otitis media. ${ }^{46,47}$ In the study by Hayden et al., ${ }^{43}$ mentioned above, which evaluated the prevention of disease transmission, the household contacts included 107 children aged 1-12 years who received weight-based unit doses of oseltamivir 30-60 mg once daily as PEP for 10 days; a separate analysis of this group showed a protective efficacy against influenza of $55 \%$. In a subsequent open-label study, none of the 49 children aged 1-12 years who received oseltamivir as seasonal prophylaxis (weight-based unit doses of 30-75 mg once daily for 6 weeks) developed laboratory-confirmed clinical influenza, although this study was not designed to show prophylactic efficacy. ${ }^{48}$

In the randomized controlled trial of oseltamivir in children aged 1-12 years, separate 
analysis of 144 children with influenza B infection showed significantly reduced duration of fever and other symptoms compared with placebo. ${ }^{46}$ More recently, a Japanese group reported that fever responded more slowly to oseltamivir in children with influenza $B$ infections than those with influenza A infections, ${ }^{49}$ although a later trial by the same group that studied oseltamivir and zanamivir found that the speed of fever resolution in treated children was similar for influenza $B$ and influenza $\mathrm{A} / \mathrm{H} 1 \mathrm{~N} 1$ infections, but slightly faster for influenza $\mathrm{A} / \mathrm{H} 3 \mathrm{~N} 2$ infections. ${ }^{50}$

\section{High-risk Population Groups}

Evidence from prospective and retrospective studies in a range of clinical settings showed that patients at higher risk of complications from influenza infection, such as young children, patients with cardiac and/or respiratory disorders, and immunocompromised adults achieve clinical benefits, such as reduced risk of pneumonia and asthma exacerbations. ${ }^{51-56}$ Moreover, oseltamivir treatment was associated with reductions in mortality risk in hospitalized patients with severe or complicated seasonal influenza, reducing risk by $79 \%$ in adults in a Toronto hospital study and by $73 \%$ in a Hong Kong hospital study, compared with no antiviral treatment. ${ }^{57,58}$

\section{Systematic Reviews and Meta-analyses}

The published evidence on the efficacy of oseltamivir in the treatment and prophylaxis of seasonal influenza has been extensively reviewed at various stages through the first 10 years of oseltamivir use. ${ }^{59-63}$ A 2009 Cochrane review of the use of neuraminidase inhibitors in adults failed to show a beneficial effect of oseltamivir on influenza complications based on data from four published studies. ${ }^{62}$ A subsequent independent re-analysis of
11 randomized controlled trials on oseltamivir, including unpublished studies that were not included in the Cochrane review, concluded that oseltamivir reduced the risk of lower respiratory tract complications which required antibiotic treatment by $28 \%$ (95\% CI, $11 \%-42 \%) .{ }^{64}$ A review published in the Cochrane database in 2007 concluded that neuraminidase inhibitors reduced the incidence of complications in children, and were effective for reducing illness duration in healthy children, although illness duration in children with asthma was not reduced significantly. ${ }^{61}$

\section{Timing of Treatment}

From trials in patients with uncomplicated seasonal influenza, it was clear that treatment with oseltamivir was most effective when given early in the course of infection. ${ }^{65-67}$ For example, in children aged 1-3 years, oseltamivir substantially reduced the median time to resolution of illness by 3.9 days (vs. placebo) $(P=0.006)$ in unvaccinated children with influenza A when given within 24 hours, and reduced the incidence of acute otitis media by $85 \%$ in children with influenza A or B when given within 12 hours. ${ }^{67}$ It has since been shown that this greater advantage of early treatment applies not only in cases of milder illness, but also in serious seasonal influenza infections in hospitalized patients (and similar infections with avian $\mathrm{H} 5 \mathrm{~N} 1$ and pandemic H1N1 viruses, as described later in this review). Lee et al. ${ }^{58}$ showed that treatment within 2 days of illness onset was associated with earlier discharge from hospital and faster discontinuation of oxygen therapy than patients who received late or no treatment. Moreover, this study also showed that treatment started within 4 days of illness onset was associated with a significant improvement in survival compared with patients who received later or no treatment. ${ }^{58}$ 


\section{Avian H5N1 Influenza}

Human infections with avian H5N1 influenza have been much more geographically restricted than seasonal influenza cases, and only 508 confirmed cases had been reported to WHO by the end of November 2010; however, H5N1 strains are much more virulent than seasonal strains, with 302 patients with confirmed infection (59.4\%) having died of the disease up to that date. ${ }^{5}$ Antiviral drugs, principally oseltamivir, have been used to treat affected patients, and pooled data from uncontrolled studies from 12 countries strongly suggested that oseltamivir treatment could reduce mortality. ${ }^{12,68}$ The WHO authors suggested, however, that treatment might be more effective at higher doses than used for seasonal influenza, a view shared by other researchers. ${ }^{69}$ Starting treatment as quickly as possible after the onset of illness was also shown to be crucial to improving survival probability, ${ }^{68,69}$ which can prove more challenging than in seasonal influenza management, because nonspecific symptoms in the first 2 days of illness can delay diagnosis. ${ }^{70}$ More recent reports on experience in Vietnamese patients support the earlier findings in demonstrating improvement in survival after oseltamivir treatment, ${ }^{71,72}$ and evidence that prophylactic use of the drug may prevent spread of human infection, not only for H5N1 influenza, but also disease caused by the H7N7 strain, was described in a recent review by Smith. ${ }^{73}$

The newest data to be published on treatment experience are those from the Roche-sponsored Avian Influenza Expert Group (AVEX) Avian Influenza Registry, which allows physicians from any country to upload new clinical data to an online database. ${ }^{12}$ The report analyzes data from 308 adults and children with human avian influenza in 12 countries, $45 \%$ of whom were male and whose median age was 17 years (range: 1-75 years;
$46 \%$ aged $<16$ years). Oseltamivir was the sole treatment for 150 patients, and for 134 other patients no receipt of an antiviral was documented. Crude survival rates were significantly better in patients who received at least one dose of oseltamivir (90/150 [60\%]) than in the no-antiviral treatment cohort (32/134 [24\%; $P<0.0001$; Figure 1]). Analysis of 221 patients for whom timing of treatment relative to symptom onset was known showed that the advantage of oseltamivir over no antiviral treatment was largest in those who began treatment within 2 days of onset (survival rates: 15/18 [83\%] and 19/95 [20\%], respectively; relative risk [RR] for survival $=4.17$ [95\% CI, 2.65-6.55; $P<0.0001])$. In patients who began treatment within 3-5 and 6-8 days of onset also, survival was significantly better in oseltamivir recipients than in those who received no antiviral treatment [ $48 \%$ vs. $27 \%$ and $50 \%$ vs. $29 \%$, respectively; $P<0.05] .{ }^{12}$

Figure 1. Kaplan-Meier survival curves showing receipt of oseltamivir compared with no antiviral treatment. ${ }^{12}$ Reproduced with permission from Adisasmito W, Chan PK, Lee $N$, et al. Effectiveness of antiviral treatment in human influenza A(H5N1) infections: analysis of a Global Patient Registry. J Infect Dis. 2010;202:1154-1160.

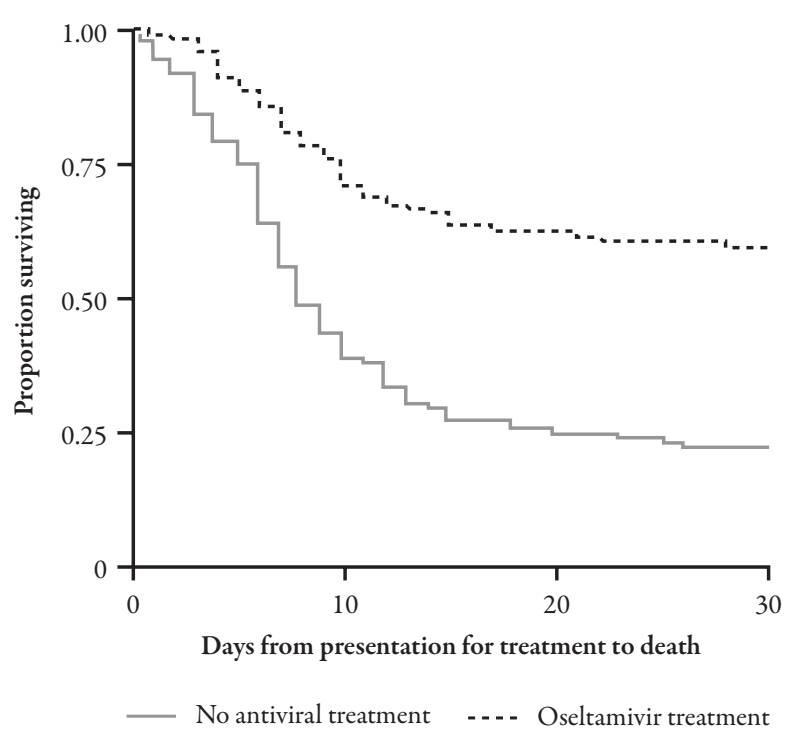




\section{Pandemic (H1N1) 2009 Influenza}

A novel H1N1 influenza virus first isolated in humans in April 2009 in Mexico reached "global pandemic" status by June 11, 2009, the first pandemic of this type since 1969, and caused disease outbreaks in most countries throughout the world by March 2010. ${ }^{4}$ The illness caused by the pandemic (H1N1) 2009 virus was mild in most cases, but as with seasonal influenza, severe symptoms and complications were seen in many patients, and at least 18,450 deaths were reported by early August 2010.4,74 Although hospitalization rates were highest in patients aged $<5$ years, fatality rates in hospitalized patients appear to have been low in children, and highest in those aged $\geq 50$ years. ${ }^{4}$ Thus far, published studies on the efficacy of oseltamivir in pandemic (H1N1) 2009 influenza have mostly reported experience in patients with severe illness, although virological findings in patients with milder disease course have also been published.

\section{Viral Clearance}

In China, Singapore, and Vietnam, a containment measure used in the early stages of the pandemic (H1N1) 2009 influenza outbreak was to isolate all patients with confirmed infection in hospital, even those with mild illness. Three studies in this setting showed that prompt oseltamivir treatment was associated with a shorter duration of viral shedding compared with those who started treatment at a later stage of illness; ${ }^{75-77}$ results of these studies are summarized in Table 2. In 167 of 179 (93.3\%)

Table 2. Summary of viral clearance results from cohorts of patients with mild pandemic (H1N1) 2009 influenza admitted to hospital for quarantine purposes, and where timing of oseltamivir treatment relative to illness onset was recorded.

\begin{tabular}{|c|c|c|}
\hline Country of study ${ }^{\text {reference }}$ & Population studied & Outcomes \\
\hline China $^{75}$ & $\begin{array}{l}\text { Quarantined patients }(n=145 ; \text { mean age } \\
20.6 \text { years; } 76 \text { aged }<18 \text { years): } 118 \text { received } \\
\text { oseltamivir ( } 83 \text { within } 48 \text { hours of illness } \\
\text { onset); } 27 \text { refused treatment }\end{array}$ & $\begin{array}{l}\text { Faster mean rate of viral load reduction in } \\
\text { patients starting oseltamivir within } 48 \text { hours } \\
(-0.638 \log 10 \text { copies } / \mathrm{mL} / \text { day post-symptom } \\
\text { onset; } 95 \% \mathrm{CI},-0.809 \text { to }-0.466) \text { than in } \\
\text { untreated patients }(-0.409,95 \% \mathrm{CI},-0.663 \text { to } \\
-0.185)\end{array}$ \\
\hline China $^{76}$ & $\begin{array}{l}\text { Quarantined adults and children }(n=426 ; \\
\text { mean age } 23.4 \text { years, } 115 \text { aged }<15 \text { years); } 351 \\
\text { received oseltamivir ( } 254 \text { within } 48 \text { hours of } \\
\text { illness onset) }\end{array}$ & $\begin{array}{l}\text { Greater risk of prolonged viral shedding in } \\
\text { patients starting oseltamivir }>48 \text { hours after } \\
\text { illness onset than in those starting within } \\
48 \text { hours (OR }=4.46,95 \% \mathrm{CI}, 2.58-7.72 \text {; } \\
P<0.001)\end{array}$ \\
\hline Singapore ${ }^{77}$ & $\begin{array}{l}\text { Quarantined individuals ( } n=70 \text {; median } \\
\text { age } 26 \text { years; IQR, 21-38 years); all received } \\
\text { oseltamivir ( } 36 \text { within } 48 \text { hours of illness } \\
\text { onset) }\end{array}$ & $\begin{array}{l}\text { Median duration of viral shedding ( } 5.0 \text { days; as } \\
\text { measured by PCR testing) significantly shorter } \\
\text { in patients starting treatment on days } 1-3 \text { of } \\
\text { illness than those starting on day } 4 \text { or later } \\
(>7.0 \text { days; } P<0.05) \text {. Two days after finishing } \\
\text { oseltamivir course, viral shedding detected in } \\
\text { significantly fewer patients treated early }(8 / 36) \\
\text { than patients treated later }(18 / 34 ; P=0.01) \text {. }\end{array}$ \\
\hline
\end{tabular}

$\mathrm{IQR}=$ interquartile range; $\mathrm{OR}=$ odds ratio; $\mathrm{PCR}=$ polymerase chain reaction. 
quarantined patients with mild pandemic H1N1 influenza in Vietnam, viral clearance as measured by reverse transcription polymerase chain reaction (RT-PCR) testing of respiratory samples was achieved 1 day after completion of 5 days oseltamivir treatment, and no virus could be isolated from any samples taken on or after that day. ${ }^{78}$ These findings agree with results of studies in seasonal influenza, both in hospitalized patients and those with milder disease. ${ }^{40,79}$

\section{Clinical Outcomes: Treatment}

Common features of the severe form of pandemic (H1N1) 2009 influenza seen worldwide were respiratory complications, such as pneumonia and acute respiratory distress syndrome (ARDS), requiring mechanical ventilation and intensive care unit (ICU) treatment. ${ }^{80-82}$ In line with findings of studies in severe seasonal and avian influenza, reports on cohorts of patients hospitalized with pandemic (H1N1) 2009 influenza (including patients in the ICU) demonstrate favorable outcomes in patients who received prompt antiviral treatment, including reduced risk of mortality, ICU admission, and respiratory failure, as well as a reduced need for mechanical ventilation. There was also a consistent association between starting treatment within 48 hours of symptom onset and better outcomes. Studies that have

Table 3A. Summary of outcomes from cohort studies and case series in adults hospitalized with severe pandemic (H1N1) 2009 influenza where early antiviral treatment (relative to illness onset) was compared with later treatment.

\begin{tabular}{|c|c|c|}
\hline Country of study ${ }^{\text {reference }}$ & Population and treatment & Outcomes \\
\hline Taiwan $^{83}$ & $\begin{array}{l}\text { Adults and children (median age, } 18 \text { years } \\
\text { [range, } 0.8 \text { months- } 73 \text { years]) with pneumonia } \\
(n=96) \text {; all received oseltamivir (numbers } \\
\text { starting treatment }>48 \text { hours and }<48 \text { hours } \\
\text { after symptom onset not stated) }\end{array}$ & $\begin{array}{l}\text { Higher risk of respiratory failure in patients } \\
\text { starting oseltamivir }>48 \text { hours after symptom } \\
\text { onset compared with patients starting within } \\
48 \text { hours (multivariate analysis: } \mathrm{OR}=16.1 \text {, } \\
95 \% \mathrm{CI}, 1.9-14.3 ; P=0.011 \text { ) }\end{array}$ \\
\hline$U^{84}$ & $\begin{array}{l}\text { Adults and children }(n=99 ; 58 \text { aged } \\
<18 \text { years); } 36 \text { received oseltamivir within } \\
48 \text { hours of symptom onset; } 40 \text { received } \\
\text { oseltamivir later than } 48 \text { hours }\end{array}$ & $\begin{array}{l}\text { Longer median duration of hospitalization in } \\
\text { patients starting oseltamivir later than earlier: } \\
3 \text { days versus } 2 \text { days; } P=0.03\end{array}$ \\
\hline $\mathrm{UK}^{85}$ & $\begin{array}{l}\text { Adults and children ( } n=2416 \text {; median age, } \\
20 \text { years); } 1299 \text { known to have received } \\
\text { antivirals, of whom } 617 \text { started treatment } \\
\text { within } 48 \text { hours of symptom onset }\end{array}$ & $\begin{array}{l}\text { Risk of admission to ICU was significantly } \\
\text { lower in those treated with antivirals within } \\
48 \text { hours of symptom onset than those who } \\
\text { started treatment later than that (OR }=0.68 \text {; } \\
95 \% \text { CI, 0.47-0.99) }\end{array}$ \\
\hline $\mathrm{US}^{86}$ & $\begin{array}{l}\text { Adults and children ( } n=47 \text {, median age, } \\
43 \text { years) with fatal severe pandemic influenza, } \\
32 \text { of whom received oseltamivir } \\
\text { Outcomes compared for } 28 \text { who were admitted } \\
\text { to ICU and died after }>24 \text { hours in hospital } \\
\text { and } 95 \text { control patients (= hospitalized and } \\
\text { survived); no data on age, number treated or } \\
\text { timing of treatment in these two subsets }\end{array}$ & $\begin{array}{l}\text { Patients who died started oseltamivir treatment } \\
\text { later than surviving patients (medians, } 6.5 \text { and } \\
3 \text { days; } P<0.01) \\
\text { Among those who received oseltamivir, } \\
\text { relatively fewer patients who died started } \\
\text { treatment within } 48 \text { hours of illness onset } \\
(15 \%) \text { compared with patients who survived } \\
(49 \%, P<0.01)\end{array}$ \\
\hline
\end{tabular}

ICU=intensive care unit; $\mathrm{OR}=$ odds ratio; $\mathrm{RR}=$ relative risk; $U K=$ United Kingdom; US=United States. 
compared the effect of early treatment initiation with a control group have shown treatment benefit in adult patients (Table $3 \mathrm{~A})^{83-86}$ as well as in vulnerable sub-populations, ie, infants, pregnant women, and immunosuppressed individuals (Table 3B). ${ }^{81,87-90}$

Further support for the value of oseltamivir in treating pandemic (H1N1) 2009 influenza comes from four other studies. In an analysis of 58 critically ill patients with confirmed, probable, or suspected pandemic influenza A (H1N1),
24 of whom died within 60 days, neuraminidase inhibitor treatment was associated with a better survival risk than no antiviral treatment $(\mathrm{OR}=8.5$ [95\% CI, 1.2-62.8]; $P=0.04)$, after excluding patients who died within 72 hours and so had less opportunity for treatment; 45 patients received one or more neuraminidase inhibitors (oseltamivir, 44; zanamivir, 6). ${ }^{82}$

In a retrospective study of patients who were hospitalized with pandemic influenza for at least 24 hours, 200 of 272 received antivirals

Table 3B. Summary of results from cohort studies and case series in high-risk patients hospitalized with severe pandemic (H1N1) 2009 influenza where timing of antiviral treatment relative to illness onset was recorded.

\begin{tabular}{|c|c|c|}
\hline Country of study ${ }^{\text {reference }}$ & Population studied & Outcomes \\
\hline Argentina $^{81}$ & $\begin{array}{l}\text { Infants and children in ICU }(n=147) \text {; } \\
135 \text { received oseltamivir }\end{array}$ & $\begin{array}{l}\text { Oseltamivir initiation within } 24 \text { hours was } \\
\text { associated with lower risk of death }(\mathrm{OR}=0.20 \text {, } \\
95 \% \mathrm{CI}, 0.07-0.54 ; P<0.01)\end{array}$ \\
\hline$U^{87}$ & $\begin{array}{l}\text { Pregnant women }(n=94) ; 30 \text { received antivirals } \\
\text { (mostly oseltamivir) within } 48 \text { hours of } \\
\text { symptom onset; } 30 \text { received antivirals later } \\
\text { than this }\end{array}$ & $\begin{array}{l}\text { Higher risk of death or ICU admission in } \\
\text { patients starting antivirals later }(\mathrm{RR}=4.3,95 \% \\
\mathrm{CI}, 1.4-13.7)\end{array}$ \\
\hline$U^{88}$ & $\begin{array}{l}\text { Pregnant women }(n=788) \text { of whom } 509 \\
\text { received antivirals ( } 476 \text { oseltamivir alone). } \\
\text { Timing of antiviral treatment known for } 384 \text { : } \\
219 \text { within } 48 \text { hours of illness onset, } 84 \text { on days } \\
3 \text { and } 4 \text {, and } 81 \text { on day } 5 \text { or later }\end{array}$ & $\begin{array}{l}\text { Patients starting antivirals on day } 5 \text { or later had } \\
\text { higher risk of mortality }(\mathrm{RR}=53.5,95 \% \mathrm{CI} \text {, } \\
7.3-391.7), \mathrm{ICU} \text { admission }(\mathrm{RR}=6.0,95 \% \\
\mathrm{CI}, 3.5-10.6) \text { and mechanical ventilation (RR } \\
=12.3,95 \% \mathrm{CI}, 5.4-27.7) \text { than those starting } \\
\text { within } 48 \text { hours }(P<0.001 \text { for all) }\end{array}$ \\
\hline $\mathrm{US}^{89}$ & $\begin{array}{l}\text { Pregnant women }(n=62) ; 53 \text { received } \\
\text { oseltamivir ( } 30 \text { within } 48 \text { hours of symptom } \\
\text { onset; } 14 \text { on day } 3 \text { or } 4 \text {; nine on day } 5 \text { or later) }\end{array}$ & $\begin{array}{l}\text { Eight women had severe illness: one }(3.3 \%) \\
\text { woman who started treatment within } 48 \text { hours, } \\
\text { three women }(21.4 \%) \text { who started treatment on } \\
\text { day } 3 \text { or } 4 \text {, and four ( } 44.4 \%) \text { who started later } \\
(P=0.002 \text { for trend by non-parametric test). }\end{array}$ \\
\hline US and Canada ${ }^{90}$ & $\begin{array}{l}\text { Solid organ transplant recipients with } \\
\text { compromised immune function }(n=237 \text {; } \\
\text { median age } 32 \text { years [range, } 1-95 \text { years]); } \\
223 \text { received neuraminidase inhibitors } \\
\text { (oseltamivir in 221), } 90 \text { within } 48 \text { hours of } \\
\text { symptom onset }\end{array}$ & $\begin{array}{l}\text { Significant association between early antiviral } \\
\text { treatment and absence of need for hospital } \\
\text { admission }(P=0.049) \text {, ICU admission } \\
(P=0.007) \text {, and mechanical ventilation } \\
(P=0.019) \\
\text { Nine deaths: } 1 / 90(1 \%) \text { in patients starting } \\
\text { antivirals within } 48 \text { hours and } 8 / 125(6 \%) \text { in } \\
\text { those starting antivirals later }(P=0.059)\end{array}$ \\
\hline
\end{tabular}

$\mathrm{ICU}=$ intensive care unit; $\mathrm{OR}=$ odds ratio; $\mathrm{RR}=$ relative risk; $\mathrm{UK}=$ United Kingdom; US=United States. 
(188 of whom were on oseltamivir). Multivariate analysis showed receipt of antiviral drugs within 2 days of onset of illness to be the only variable significantly associated with a positive disease outcome. ${ }^{80}$ Surveillance of 1088 patients with severe illness found that substantially higher proportions of those that survived had received antiviral treatment within 48 hours of symptom onset, compared with those who died, but the authors did not report the number of patients who received oseltamivir, and did not test for statistical significance of the differences between fatal and non-fatal cases. ${ }^{91}$ Favorable outcomes were also reported in patients with mild influenza: in approximately 4570 patients with confirmed pandemic (H1N1) 2009 influenza who received prompt antiviral treatment (oseltamivir, 99.4\% of cases) after presenting to emergency rooms, 11 needed ICU treatment and none died..$^{92}$

Retrospective analysis of cases reported to the French public surveillance system suggested a protective effect of early antiviral treatment, with those receiving oseltamivir within 48 hours of illness onset being significantly less likely to develop serious infection or to die than those treated later or not at all, ${ }^{93}$ and a similar association was shown in a Canadian casecontrol study, in which patients treated within 48 hours of illness onset had a lower probability of admission to hospital or ICU than those treated more than 48 hours after onset. ${ }^{94}$

\section{Clinical Outcomes: Prophylaxis}

Preventing disease spread in the early stages of the pandemic outbreak was a priority in many national management plans, and outcomes of containment strategies involving oseltamivir prophylaxis were reported in detail by three groups.

A ring prophylaxis intervention strategy was used to contain outbreaks of pandemic (H1N1)
2009 influenza in four Singapore military units: this entailed isolating index cases (confirmed infections), segregating affected units from others, and giving all co-workers of the index case (1100 of 1175 at-risk personnel) oseltamivir $75 \mathrm{mg}$ daily for 10 days. ${ }^{95}$ Infection rates were significantly lower after the intervention than beforehand based on reduction of the reproductive number (R0; number of new cases attributable to the index case), whether based on confirmed cases only (1.91-0.11) or confirmed and untested symptomatic cases (1.85-0.28; $P<0.001$ for both analyses). Before and after the intervention, the total individuals infected were $75(6.4 \%)$ and seven (0.6\%), respectively. Oseltamivir was well tolerated, with no serious adverse events (AEs) reported..$^{95}$

The other two groups investigated disease transmission from index cases to household contacts. The first study related to the first outbreak of pandemic (H1N1) 2009 influenza in Osaka, Japan. ${ }^{96}$ The secondary attack rate (SAR) in 379 contacts from 124 separate households was determined according to whether contacts received PEP $(n=333)$ or not $(n=46)$; of those receiving PEP, 232 (69.7\%) took oseltamivir, $62(18.6 \%)$ took zanamivir, two took both, and 36 received an un-named drug. Two of the 14 contacts who developed influenza were in the PEP group and 12 in the no-PEP group, producing estimated SARs of $26.1 \%$ and $0.6 \%$, respectively, and a RR of transmission of 0.023 (95\% CI, 0.005-0.100; P<0.001). ${ }^{96}$ The second group reported on transmission of pandemic (H1N1) 2009 influenza from 65 Hong Kong schoolchildren to 205 household contacts. ${ }^{97}$ Twelve contacts developed influenza, giving an estimated SAR of 5.9\% (95\% CI, 2.7-9.1) for all contacts; however, the SAR for the group who did not receive oseltamivir prophylaxis was $8.5 \%$ $(12 / 141$ contacts), and for contacts who did receive prophylaxis was $0 \%(0 / 64 ; 95 \% \mathrm{CI}, 0-0.9)$. 
The authors gave no details on either the dosage of oseltamivir or its tolerability. ${ }^{97}$

\section{RESISTANCE}

\section{Implications and Mechanism}

OC binds to the influenza neuraminidase active site and inhibits neuraminidase enzyme activity - this reduces the ability of the influenza virus to migrate through lung mucus layers and reduces the rate of release of new influenza virions from infected cells. These changes limit the spread of virus infection and reduce the duration and severity of the infection. The susceptibility of influenza virus neuraminidase to inhibition by OC can be increased (hypersusceptibility) or decreased (resistance) by mutations in the neuraminidase coding sequence. Such genetic mutations may arise naturally through spontaneous mutation, or may be drug-induced, when virus replication occurs under selection pressure in the presence of a neuraminidase inhibitor.

Changes in the susceptibility of viral neuraminidase to inhibition by neuraminidase inhibitors are related to changes in inhibitor binding affinity to the enzyme active site: mutations that increase inhibitor binding affinity can increase susceptibility of neuraminidase to inhibition, whereas mutations that decrease inhibitor binding affinity can reduce susceptibility and may confer resistance to inhibition. The most common OC resistance mutation is the $\mathrm{H} 275 \mathrm{Y}$ mutation (where tyrosine replaces histidine at position 275 on the N1 subtype neuraminidase). The degree of resistance to oseltamivir conferred by this mutation is specific to influenza subtype, ie, resistance occurs in N1 neuraminidase subtypes, such as $\mathrm{H} 1 \mathrm{~N} 1$ or $\mathrm{H} 5 \mathrm{~N} 1$ viruses, but not in other subtypes, such as H3N2 or influenza B viruses. The $\mathrm{H} 275 \mathrm{Y}$ mutation also confers resistance in a drug-specific manner. While N1 subtype neuraminidases are highly resistant to inhibition by OC, this mutation does not affect inhibition of neuraminidase by zanamivir. Other mutations confer resistance specifically to other virus subtypes or to other neuraminidase inhibitors, such as zanamivir and peramivir.

As the neuraminidase active site is highly conserved and essential for virus replication, mutations that confer neuraminidase inhibitor resistance often affect the replication fitness and transmissibility of viruses, ${ }^{98}$ and have therefore been rare in circulating influenza virus strains. An exception was an H1N1 virus that emerged in Europe in 2007 that carried the H275Y resistance mutation in a compensatory sequence background, and became the predominant H1N1 strain for two influenza seasons. Studies have indicated that the replication fitness and transmissibility of H1N1 and H5N1 virus strains carrying the $\mathrm{H} 275 \mathrm{Y}$ mutation can vary.

The clinical presentation of influenza in immunocompetent patients who are infected with oseltamivir-resistant H1N1 viruses is very similar to disease caused by oseltamivirsusceptible viruses, and the frequencies of secondary complications and outcomes also appear to be similar. ${ }^{99,100}$ To date, all cases of drug-induced resistance in immunocompetent patients have been observed only transiently during the infection, and the virus in question was eventually cleared with no evidence of transmission. However, close monitoring of sequence evolution and emergent resistant viruses with different sequence backgrounds is essential to enable early recognition of trends towards increased fitness, transmissibility or pathogenicity of viruses that result from antigenic drift. Antiviral resistance may emerge more often in immunocompromised patients who require a prolonged treatment duration; in these patients, and in patients infected 
with highly pathogenic viruses such as H5N1, resistance poses a higher risk than normal - such patients should be intensively monitored for resistance emergence during treatment.

\section{Drug-Induced Resistance Versus Natural Resistance}

Drug-induced resistance is defined as the emergence of a drug-resistant virus isolate in a treated patient who was infected with a drugsensitive virus before treatment. In contrast, the term natural resistance is used to describe the emergence of a drug-resistant virus in an individual who has not been exposed to drug or been in close contact with somebody who has received drug treatment.

Drug-induced resistance selection during treatment of immunocompetent persons with oseltamivir is currently rare. As reviewed in an article by Aoki and colleagues, ${ }^{98}$ the rate of druginduced resistance found in Roche-sponsored clinical trials in seasonal influenza virus infections was low. In all, $0.4 \%$ of adults (5/1245) and $5.4 \%$ of children $(25 / 464)$ had detectable oseltamivir-resistant virus at one or more time points during treatment. ${ }^{98}$ The rate of resistance in children was higher in two studies $(9 / 50$ [18.0\%] and 7/43 [16.3\%], respectively) in which suboptimal doses were given. ${ }^{101,60}$ In a small study of children who received oseltamivir at standard weight-based dosages during 2005-2007, overall drug-induced resistance incidence was $6.3 \%(4 / 64)$, similar to the overall incidence reported by Aoki and colleagues. Breakdown of resistance incidence by virus subtype was $27.3 \%$ (3/11) for H1N1 strains, $2.9 \%(1 / 34)$ for H3N2, and $0 \%(0 / 19)$ for influenza $B$. The significance of the apparent increased rate of resistance in H1N1 virus infections in children remained unresolved because of the small number of cases, but nevertheless suggests a possibility of subtype or strain-specific differences in the barrier to resistance. ${ }^{102}$

The results from worldwide surveillance of oseltamivir resistance are consistent with a relatively low incidence of resistance in controlled clinical studies. While 36 million courses of oseltamivir were prescribed in Japan from its introduction in 1999 through to 2007,103 $99.7 \%$ of viral isolates tested in Japan between 2003 and 2007 were susceptible to oseltamivir, ${ }^{104}$ and a similar proportion of susceptible strains (99.7\%) was found by worldwide surveillance between 1999 and 2002. ${ }^{105}$

Notably, a global surveillance report in early 2008 found a very low rate of resistant mutations in samples from 2004-2007, but also recorded a pronounced increase in incidence of H1N1$\mathrm{H} 275 \mathrm{Y}$ viruses in a preliminary analysis of 2007-2008 isolates, with an incidence of resistance in all samples of $6.4 \%$ (57/896 isolates), most coming from the US. ${ }^{106}$ The 2007-2008 and 2008-2009 winter seasons in the northern hemisphere and the 2008 season in the southern hemisphere were marked by the emergence of a naturally-resistant influenza A H1N1-H275Y virus, which was first described in Norway in 2007 and then became the predominant H1N1 virus strain worldwide from the middle to the end of 2008, although H3N2 and B virus infections were also prevalent during this time. This new H1N1 virus replaced the previous seasonal H1N1 virus in Europe, reaching an overall prevalence of $24 \%(712 / 2948$ isolates tested) of H1N1 isolates in the 2007-2008 season. In that season, 60\% of collected samples in Europe were influenza A and $40 \%$ influenza B, with $96 \%$ of the influenza A samples being the H1 subtype: thus, $14 \%$ of influenza virus infections in Europe were with oseltamivir-resistant virus, and $86 \%$ of infections with oseltamivir-sensitive virus. ${ }^{107}$

A study during the 2007-2008 season found that the prescription rate for oseltamivir in 
12 European countries had not risen from the average level of the previous 6 years, and that there was no correlation between the oseltamivir prescription volumes and prevalence of the $2007 \mathrm{H} 1 \mathrm{~N} 1-\mathrm{H} 275 \mathrm{Y}$ virus, consistent with the emergence and spread of resistance to oseltamivir in these viruses that was independent of drug use. ${ }^{108}$ While the European influenza season of 2007-2008 was dominated by influenza A (H1N1) and influenza B infections, the following season (2008-2009) was mostly associated with influenza A (H3N2) infections. Of 3696 isolates collected between week 40 of 2008 and week 19 of 2009, 2564 (69.4\%) were H3N2, 166 (4.5\%) were H1N1, 965 (26.1\%) were influenza B, and there was a single isolate of new pandemic influenza H1N1 (2009); so despite 98\%-99\% of seasonal H1N1 sequences being oseltamivir-resistant H1N1-H275Y, more than 95\% of influenza virus infections in Europe during the 2008-2009 season were with oseltamivir-sensitive H3N2 or B viruses. ${ }^{109}$ The switch in prevalence in the US over the same two seasons, however, was the reverse of that in Europe: 2007-2008 was H3N2-dominated and 2008-2009 was H1N1dominated. Moreover, the spread of the naturally oseltamivir-resistant H1N1-H275Y variant in the US was slower than in Europe, with a prevalence among H1N1 isolates of $12.3 \% .{ }^{99}$ Only $2.3 \%$ of all influenza infections in the US during 2007-2008 were with oseltamivir-resistant viruses, but this changed markedly in 2008-2009, when approximately $60 \%$ of influenza infections were with $\mathrm{H} 1 \mathrm{~N} 1$ viruses, 99\% of which were the H1N1-H275Y strain; the remaining $40 \%$ of influenza viruses (mostly type B) were sensitive to inhibition by oseltamivir. ${ }^{110}$

For this H1N1-H275Y virus variant to emerge, with a sufficiently high replication capacity to permit onward transmission, the presence of a permissive sequence background was required, and a number of candidate mutations in neuraminidase $(\mathrm{H} 45 \mathrm{~N}, \mathrm{~K} 78 \mathrm{E}$, E214G, R222Q, G249K, T287I, K329E, D344N, D382N) were described by Rameix-Welti et al. ${ }^{111}$ using sequence analysis. This group reported a significant increase in neuraminidase binding affinity for sialic acid substrate among the earlier oseltamivir-sensitive viruses from the 2007-2008 season, which may have affected fitness, while the introduction of the $\mathrm{H} 275 \mathrm{Y}$ mutation reduced binding affinity to more typical H1N1 levels, and may have restored more optimal balance between hemagglutinin and neuraminidase binding affinities for sialic acid substrates. ${ }^{111}$ It was recently shown that the presence of the $\mathrm{H} 275 \mathrm{Y}$ mutation can reduce the amount of neuraminidase that reaches the cell surface during protein synthesis, and that some of the candidate compensatory mutations could reverse that defect. ${ }^{112}$

Natural variation of the neuraminidase sequence is mostly driven by antigenic drift (immune selection), as neuraminidase, like hemagglutinin, is targeted by the host immune response. As influenza viruses evolve to circumvent host immune response and immune memory, specific antigenic patterns may be maintained only for a limited time period before being replaced by new virus variants. Thus, when global population immunity has reached a threshold level that will prevent productive spread of the H1N1$\mathrm{H} 275 \mathrm{Y}$ virus, antigenic drift is expected to lead to its replacement by an antigenically different H1N1 virus, also driven by immune selection. For example, northern hemisphere seasons dominated by H1N1 virus infections have generally been followed by H3N2-dominated seasons, as was observed in 2007-2008 and 2008-2009 in Europe. The oseltamivir-resistant seasonal H1N1 virus has now been almost completely replaced by pandemic $\mathrm{H} 1 \mathrm{~N} 1$ 
(2009) virus, which became the dominant virus in the 2009-2010 season worldwide. Early indications are that the 2010-2011 season may see an increase in H3N2 infections, consistent with widespread global exposure and immunity to pandemic (H1N1) 2009 virus.

\section{Resistance in Avian Influenza Viruses}

To date, resistance to oseltamivir in avian H5N1 viruses has been rare. Of 55 strains of H5N1 virus from Australia and South-East Asian countries analyzed between 2004-2006, 53 were sensitive to neuraminidase inhibitors with half maximal inhibitory concentration (IC50) values that were similar to those for H1N1 strains circulating in this region between 2001 and 2006, and the two less sensitive strains had IC50 values of 5.38 and $3.59 \mathrm{nmol} / \mathrm{L}$, which would be expected to be sensitive to oseltamivir treatment at recommended doses. ${ }^{113} \mathrm{~A}$ more recent analysis of $\mathrm{H} 5 \mathrm{~N} 1$ genome sequences that found five of 676 isolates had potential resistance mutations (N294S, one; H275Y, four) predicted susceptibility to oseltamivir in $>99 \%$ of circulating H5N1 strains, and concluded that drug-resistant strains typically arose through independent point mutations in the neuraminidase. ${ }^{114}$ Patients from Vietnam and Egypt from whom oseltamivirresistant viruses were isolated with N294S and/ or $\mathrm{H} 275 \mathrm{Y}$ mutations have been described in published case reports. ${ }^{115-117}$ Currently, the incidence of selection of resistance during treatment of H5N1 infection with oseltamivir is low, and appears similar to that observed during treatment of seasonal virus infections.

\section{Resistance in Pandemic Influenza (H1N1) 2009 Viruses}

Statistics from WHO published in August 2010 show that the pandemic (H1N1) 2009 virus was the predominant influenza strain worldwide from week 20, 2009 (mid-April) until the end of week 5, 2010 (early February), ie, throughout both the southern hemisphere and northern hemisphere winter seasons. ${ }^{118}$ Other influenza viruses (particularly type B) were equally or more prevalent from mid-February onwards. Thus, the seasonal H1N1 subtypes with naturallyacquired resistance to oseltamivir described above have almost disappeared from the circulating influenza virus population globally, to be replaced mainly by pandemic (H1N1) 2009 viruses. Resistance to oseltamivir in the pandemic (H1N1) 2009 virus has thus far been sporadic and geographically dispersed, with no evidence that the resistant strains are circulating within communities. ${ }^{15}$ The great majority (>99\%) of over 20,000 clinical specimens or isolates of the pandemic (H1N1) 2009 virus tested across the six international WHO regions (over 85 countries) up to February 2010 were sensitive to oseltamivir, as shown in Table $4 .^{15}$

The pandemic (H1N1) 2009 virus is antigenically and genetically distinct from the oseltamivir-resistant seasonal influenza A (H1N1) virus, with a genetic make-up from North American and Eurasian swine virus lineages. ${ }^{119}$ No evidence of re-assortment between pandemic (H1N1) 2009 and other seasonal influenza viruses has been found. ${ }^{15}$

From April 2009 to August 2011, the cumulative total of oseltamivir-resistant pandemic (H1N1) 2009 viruses reported to WHO was $566 .{ }^{120}$ Considering just the 436 cases for which information on clinical background was reported, most (305 [70\%]) were in patients with normal immune function, and 131 (30\%) were in immunosuppressed patients. In the patients with normal immune function, 210 cases were associated with drug use (for treatment or PEP), and 95 cases were not associated with any drug use (Figure 2). ${ }^{120}$ 
Table 4. Number of oseltamivir-resistant pandemic (H1N1) 2009 isolates in each World Health Organization (WHO) region, compared with number of isolates and clinical specimens tested for susceptibility, as of February 15, 2010.15

\begin{tabular}{lcc}
\hline WHO region & Resistant isolates & Total tested \\
\hline Africa & 0 & 66 \\
Eastern Mediterranean & 1 & 50 \\
Europe & 77 & $>7500$ \\
Americas & 65 & $>8000$ \\
South-East Asia & 0 & 20 \\
Western Pacific & 82 & $>7500$ \\
\hline
\end{tabular}

Prolonged viral replication and lack of immune-mediated virus clearance in immunosuppressed patients treated with antivirals can result in a higher incidence of selection of drug-resistant viruses, a phenomenon that has been documented previously. ${ }^{121}$ Surveillance of 1608 hospitalized patients with pandemic (H1N1) 2009 influenza in Edinburgh and Glasgow found resistant virus in 10 patients (all immunocompromised) in a 2-month period. ${ }^{122} \mathrm{~A}$ few of the resistant isolates of pandemic (H1N1) 2009 collected from immunosuppressed patients have occurred in clusters, such as the hospital outbreaks in Cardiff, UK and Duke University, US, and are believed to have involved person-to-person transmission. ${ }^{15}$ A report from an Australian group describes four immunocompromised patients with resistant influenza virus, most of whom acquired infections in the community rather than nosocomially. ${ }^{123}$ Influenza isolates obtained from two immunocompromised patients infected with pandemic (H1N1) 2009 influenza identified a new mutation in the neuraminidase (I223R), either alone or in combination with $\mathrm{H} 275 \mathrm{Y}$, that can confer moderate resistance to both oseltamivir and zanamivir. ${ }^{124,125}$

As of August 18, 2010, 6\% of all cases of oseltamivir resistance reported to WHO were in individuals with normal immune function who received oseltamivir as prophylaxis, and additional (unquantified) cases of resistance have been reported in immunosuppressed patients on a prophylactic regimen. ${ }^{126}$

Figure 2. Breakdown by clinical setting of cases of oseltamivir-resistant viruses reported to World Health Organization up to August 10, 2011. ${ }^{121}$

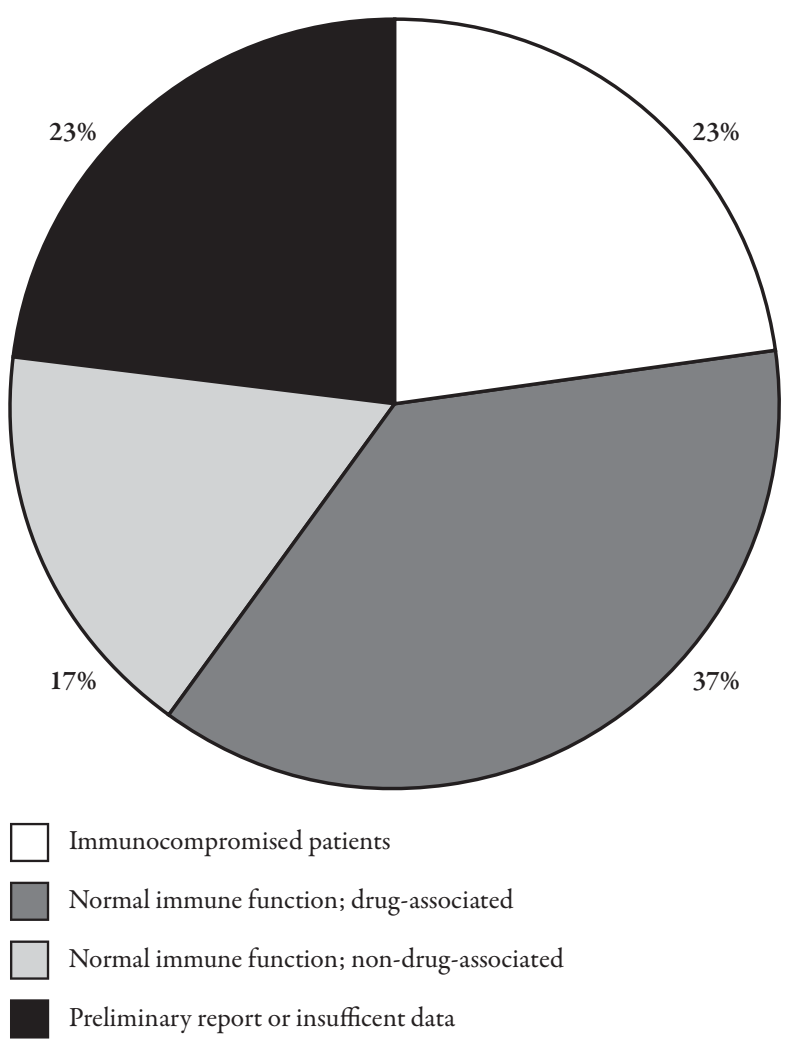


Case reports on some of these individuals have been reported separately. ${ }^{127-129}$

The low number of oseltamivir-resistant viruses in patients with pandemic (H1N1) 2009 influenza is consistent with lower fitness and/or transmissibility of the resistant variants compared with the sensitive variants of the virus. Reduced transmissibility of H1N1 viruses carrying a single $\mathrm{H} 275 \mathrm{Y}$ point mutation in the neuraminidase coding sequence has been described previously for seasonal H1N1 viruses. ${ }^{15,98}$ Additional compensatory mutations are expected to be required to allow more efficient replication or transmission of oseltamivir-resistant viruses. Data from animal studies on pandemic (H1N1) 2009 viruses suggested that resistant strains have either reduced transmissibility or similar fitness and transmissibility compared with sensitive strains. ${ }^{130-132}$ The reasons for the differences in observations are unclear, but may be related to the use of different virus strains in these studies, or the low number of animals used. The possibility of natural emergence of compensatory mutations or compensated resistance mutations to neuraminidase inhibitors warrants continued close surveillance of sequence evolution in influenza viruses.

\section{SAFETY}

\section{Safety in Adults and Adolescents Established in Controlled Clinical Trials}

Cumulative safety and tolerability data for oseltamivir use in adults and adolescents in randomized controlled trials come from 4592 study participants exposed to oseltamivir, 2647 of whom received it as treatment and 1945 of whom received it for influenza prophylaxis. Clinical trial experience in children and other groups is described below (see Safety in Special Populations). In treatment studies, the most frequently reported AEs were nausea, vomiting, and headache. The majority of these events were reported on a single occasion, usually on the first or second treatment day, and resolved spontaneously within 1-2 days without the need to stop treatment. In prophylaxis studies, the safety profile was similar, despite a longer duration of dosing: nausea, vomiting, headache, and pain were the most frequently reported AEs (Table 5). Other AEs were reported in $\geq 1 \%$ of oseltamivir recipients in the treatment and prophylaxis studies, but at a similar or lower incidence compared with placebo recipients. These included many symptoms and complications that are typical of influenza infection, including nasal congestion, cough, sore throat, muscular or joint pain, diarrhea, abdominal pain, fatigue, and dizziness, as well as infections (such as bronchitis and upper respiratory tract infections), dysmenorrhea, and insomnia (Roche, data on file).

\section{Post-Marketing Surveillance}

Other AEs in people receiving oseltamivir have been identified from spontaneous reports received during post-marketing use. Hypersensitivity reactions, many of which were allergic skin reactions, such as dermatitis, eczema, erythema multiforme, Stevens-Johnson syndrome (SJS), and toxic epidermal necrolysis have been reported. ${ }^{6,7,133}$ Hepatitis and elevated liver enzymes have also been reported in patients with ILI receiving oseltamivir, and cases of gastrointestinal bleeding. ${ }^{6,7}$

Two recent reports described a possible association between oseltamivir and cardiovascular effects. In the first report, torsades de pointes (a form of ventricular tachycardia) occurred in two women who had been previously treated with sotalol for arrhythmias and were given oseltamivir for confirmed or 
Table 5. Adverse drug reactions reported in $\geq 1 \%$ of patients in the oseltamivir group in studies investigating oseltamivir for the treatment or prevention of influenza in adults and adolescents and in post-marketing surveillance (pooled analysis). ${ }^{6}$

\begin{tabular}{|c|c|c|c|c|}
\hline & \multicolumn{4}{|c|}{ Proportion of patients (\%) who reported events } \\
\hline & \multicolumn{2}{|c|}{ Treatment } & \multicolumn{2}{|c|}{ Prevention } \\
\hline & $\begin{array}{l}\text { Oseltamivir } 75 \mathrm{mg} \\
\text { twice daily }(n=1057)\end{array}$ & Placebo $(n=1050)$ & $\begin{array}{c}\text { Oseltamivir } 75 \mathrm{mg} \\
\text { once daily }(n=1480)\end{array}$ & Placebo $(n=1434)$ \\
\hline Bronchitis & 4 & 5 & 1 & 1 \\
\hline Bronchitis acute & 1 & 1 & 0 & $<1$ \\
\hline Upper respiratory tract infection & 0 & 0 & 8 & 8 \\
\hline Headache & 2 & 2 & 20 & 18 \\
\hline Insomnia & 1 & 1 & 1 & 1 \\
\hline Vertigo & 1 & 1 & $<1$ & $<1$ \\
\hline Cough & 1 & 1 & 6 & 6 \\
\hline Rhinorrhea & $<1$ & 0 & 2 & 1 \\
\hline Nausea $^{*} \dagger$ & 11 & 7 & 8 & 4 \\
\hline Vomiting $\dagger$ & 8 & 3 & 2 & 4 \\
\hline Abdominal pain & 2 & 2 & 2 & 2 \\
\hline Diarrhea & 6 & 8 & 3 & 3 \\
\hline Dyspepsia & 1 & 1 & 2 & 2 \\
\hline Dermatitis & $<1$ & $<1$ & 1 & 1 \\
\hline Dizziness & 2 & 3 & 2 & 2 \\
\hline Fatigue & 1 & 1 & 8 & 8 \\
\hline Pain & $<1$ & $<1$ & 4 & 3 \\
\hline
\end{tabular}

*Subjects who reported nausea alone (without vomiting).

†Statistically significant difference between oseltamivir and placebo.

suspected influenza; in one of these women, the causative relationship was doubtable, occurring 6 days after treatment finished, although prolongation of the QT interval corrected for heart rate (QTc) was observed during the treatment course. ${ }^{134}$ In the second report, two women treated with oseltamivir for suspected pandemic (H1N1) 2009 influenza developed bradycardia. ${ }^{135}$ The results of a retrospective cohort study, however, suggest that the risk of recurrent adverse cardiovascular outcomes such as heart failure and sudden cardiac death in patients with existing cardiovascular disease is lower in those treated with oseltamivir than those not treated, ${ }^{136}$ and a similar benefit has been shown with respect to stroke and transient ischemic attacks. ${ }^{137}$ An expert review of data from preclinical and clinical studies, published literature, and spontaneous reports in the Roche Drug Safety database indicates no association between oseltamivir treatment and cardiac arrhythmias, other cardiac disorders, or sudden death in adults or children, and no increased susceptibility to cardiac events in Japanese individuals (Hoffmann-La Roche, data on file). 


\section{Neuropsychiatric AEs}

Various neuropsychiatric AEs (NPAEs) have been reported during oseltamivir administration, mainly in children and adolescents. These have included convulsions as well as delirium-like symptoms, such as altered consciousness, confusion, abnormal behavior, delusions, hallucinations, agitation, anxiety, and nightmares, and in some cases, have resulted in accidental injury. Although NPAEs were described in patients with influenza infection before the introduction of oseltamivir, ${ }^{138-140}$ reports of such events during 2005-2006, principally in Japanese patients, suggested that they were associated with oseltamivir treatment. ${ }^{141}$ In January 2008, the US product label was changed following guidance from the Pediatric Advisory Committee of the US Food and Drugs Administration; the changes included a description of neuropsychiatric symptoms that can occur during influenza infection, irrespective of drug therapy, and noted the uncertain causality of such symptoms. The new labeling also notes that symptoms can appear abruptly and that "injurious behavior" includes fatal outcomes. Similar labeling changes were recommended for other antiviral influenza medications.

In 2008, Roche published an assessment of influenza-associated NPAEs in patients who had received oseltamivir. ${ }^{103}$ The article included a wide range of evaluations aimed at assessing the prevalence and genesis of such events. It included post-marketing surveillance of spontaneously reported AEs, prospective clinical trial data, and results of large retrospective observational studies based on US health claims data. This was supplemented by results of pharmacokinetic studies in humans and animals, analysis of possible genetic factors, and pharmacodynamic interactions with neurotransmitter and transport mechanisms and metabolic pathways. The article concluded that the data then available did not indicate that oseltamivir administration increased the risk of
NPAEs in influenza patients, and no mechanism through which oseltamivir or its metabolites could cause or aggravate such events could be identified, although a contribution from the drug could not be conclusively ruled out at that stage. ${ }^{103}$ More recently, an additional analysis of a large patients claims database produced results consistent with those summarized in the review by Toovey et al., ${ }^{103}$ showing that influenza patients treated with oseltamivir had a lower risk of NPAEs than patients who receive no antiviral treatment. ${ }^{142}$

In early 2010, a new comprehensive safety evaluation on oseltamivir was performed, to determine whether any new safety signals emerged during the period when pandemic (H1N1) 2009 virus was the dominant strain, and to assess tolerability and safety in the patient sub-populations that had been underexposed to oseltamivir up to that point. ${ }^{143}$ This evaluation compared reports of AEs in the US and Japan during the first 8 months of the 2009 influenza pandemic (May 1-December 31, 2009) with post-marketing reports during the pre-pandemic period, ie, before May 1, 2009. The analysis did not indicate that any new safety signals emerged during the pandemic period, and also showed that NPAEs were significantly less common (crude reporting rates per million exposures) during the pandemic than the pre-pandemic period. ${ }^{143}$

\section{Safety in Special Populations}

\section{Children}

Safety data on children aged 1-12 years with seasonal influenza have demonstrated that oseltamivir is well tolerated with a similar AE profile to placebo (Table 6). In a pooled analysis of four treatment studies in 1032 children given the $2 \mathrm{mg} / \mathrm{kg}$ dose twice daily for 5 days, the only events that occurred more frequently in the oseltamivir group were vomiting (15\% vs. 9\%), abdominal pain ( $5 \%$ vs. $4 \%$ ), and ear disorders 
( $2 \%$ vs. $1 \%$, with the gastrointestinal events usually occurring at the start of treatment and resolving rapidly. ${ }^{144}$ Gastrointestinal symptoms were also the most commonly reported events in two prophylaxis studies, where treatment duration was either 10 days or 6 weeks, and the AEs seen were generally mild to moderate in intensity. ${ }^{43,145}$

In May 2009, the typical circulating seasonal influenza strains including $\mathrm{H} 1 \mathrm{~N} 1$ viruses were almost completely replaced by pandemic (H1N1) 2009 virus. Regulatory bodies in the US and
Europe responded to this development by giving emergency use authorization (EUA) for the use of oseltamivir in additional patient groups, including infants $<1$ year old. ${ }^{146,147}$ The decision made by the European Medicines Agency (EMA) in September 2009 to approve treatment and prevention indications in infants $<1$ year of age was based on a review by the Committee for Medicinal Products for Human Use (CHMP). ${ }^{146}$ The data reviewed by CHMP included interim pharmacokinetic and safety data from the prospective study, CASG114, (US National Institutes of Health; ClinicalTrials.

Table 6. Adverse drug reactions reported in $\geq 1 \%$ of patients in the oseltamivir group in studies investigating oseltamivir for the treatment or prevention of influenza in children and in post-marketing surveillance (pooled analysis). ${ }^{6}$

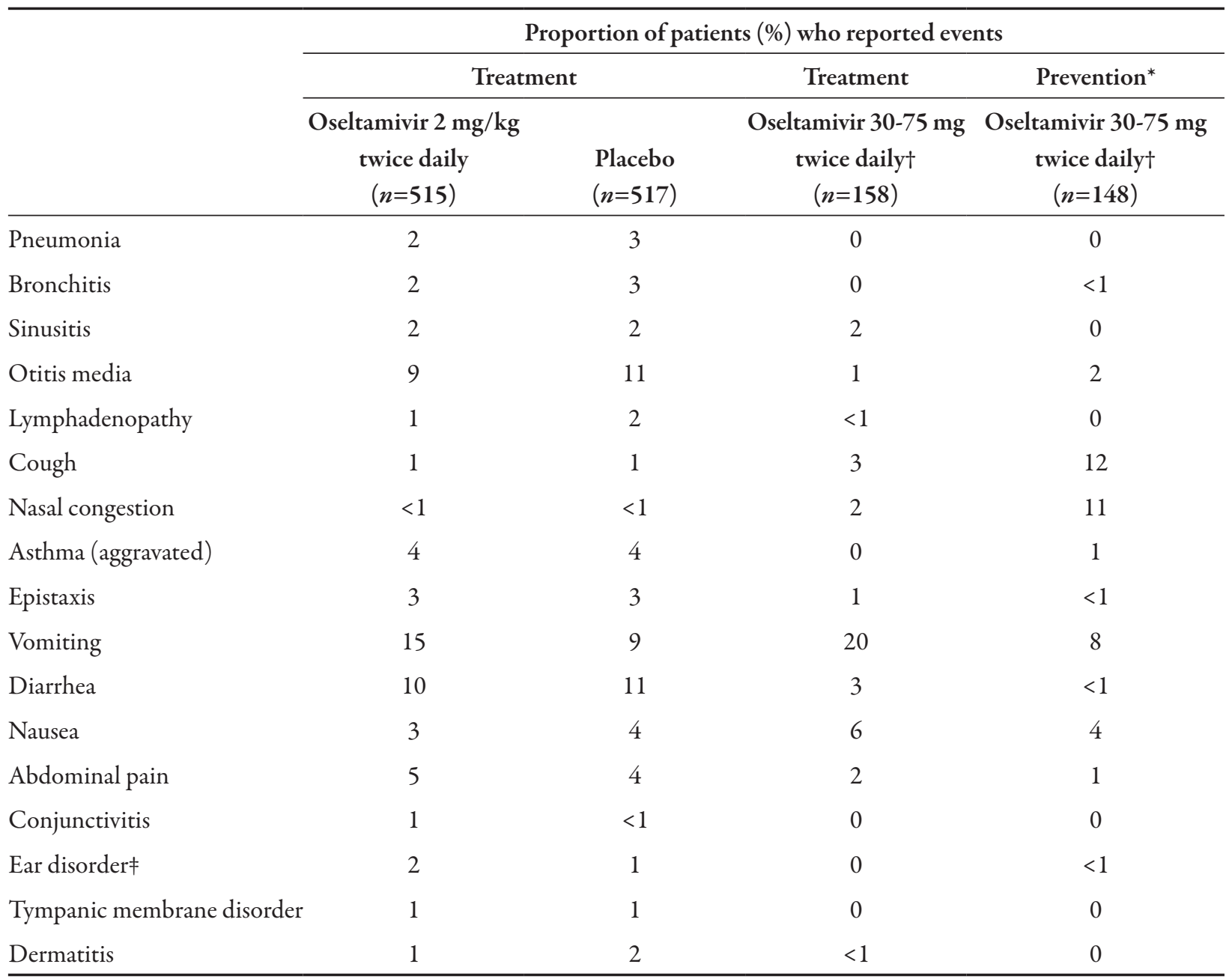

*This study had no placebo arm.

tWeight-based dosing.

$\neq$ Earache and pain in the ear. 
gov identifier: NCT00391768) in children aged $<2$ years, safety data from Japanese interventional and surveillance studies, and a German hospital study (see below). On the strength of these data it was concluded that the benefit of using oseltamivir for the treatment and PEP of infants $<1$ year old outweighed the risk in the context of pandemic influenza. Recommendations for updating the product's label were therefore made, including dosages to treat children 0-6 months old who are infected with pandemic influenza, and to prevent illness in children $<1$ year old who are exposed to pandemic influenza. ${ }^{146}$ Since the EMA's review, the results of the German hospital study in infants aged $<1$ year has been published. This retrospective analysis showed that oseltamivir was generally well tolerated: only one of the 157 infants failed to complete the 5-day oseltamivir course because of an AE (repeated vomiting), and AEs were seen in 78 (50\%) infants, the majority being vomiting or diarrhea of mild intensity. ${ }^{148}$

The Roche safety evaluation that assessed tolerability and safety of oseltamivir during the first 8 months of the 2009 influenza pandemic (see Neuropsychiatric AEs) evaluated four patient sub-populations, one of which was infants $<1$ year old. Spontaneous AEs from the Roche database and serious adverse events (SAEs) from clinical trials during the period of May 1-December 31, 2009 were medically reviewed. During this period, 107 events were reported in 74 infants, one of whom died (from influenza complicated by ARDS/viral pneumonia). Of 24 other (non-fatal) SAEs, the associated terms were either typical findings in infants with febrile viral infections, like rashes and convulsions, or considered to be related either to other current illness or medications. ${ }^{143}$

\section{Pregnant Women}

The decision to recommend the use of oseltamivir in pregnant and lactating women in the context of pandemic (H1N1) 2009 influenza ${ }^{147,149}$ was based on the results of an analysis of 232 maternal exposures to oseltamivir during pregnancy from Roche's safety database. ${ }^{150}$ That analysis has since been substantially expanded as a result of the increased use of oseltamivir during the 2009-2010 pandemic. This assessment of 1335 maternal exposures over a 10-year period, where pregnancy and fetal outcomes were known for 618 and 569 women, respectively, suggests that oseltamivir is unlikely to cause adverse pregnancy outcomes (spontaneous and therapeutic abortions and pre-term delivery) or fetal outcomes (birth defects) (Roche, data on file). These results were in line with those of a retrospective analysis by a US group who assessed the safety of antiviral agents during pregnancy by comparing 239 mothers exposed to these agents with roughly 82,000 unexposed controls, and found no effect on maternal and neonatal outcomes of antepartum exposure to oseltamivir or M2 ion channel inhibitors, such as amantadine. ${ }^{151}$ The pandemic-specific safety evaluation referred to above also reviewed data on pregnant women, and found no evidence of AEs of oseltamivir in 207 maternal exposures. ${ }^{143}$

\section{Immunocompromised Individuals}

Two groups have reported safety and tolerability data on oseltamivir in immunocompromised patients in the seasonal influenza setting. In the first of these, ${ }^{152}$ the AE profile in 45 individuals aged 11-73 years who were undergoing hematopoietic stem cell transplantation (HSCT) and received oseltamivir as post-exposure prevention following an influenza outbreak was similar to that in matched untreated controls; most of the events reported were gastrointestinal symptoms, such as nausea and vomiting, and the incidence of these was similar to controls, although abdominal pain was more common in the treated group. No deaths were attributable 
to oseltamivir. ${ }^{152}$ In a later study in solid organ and HSCT recipients receiving a 12-week oseltamivir course for seasonal influenza prevention, the incidence of AEs and SAEs was found to be very similar for oseltamivir and placebo, with gastrointestinal disorders again being the most frequent AEs recorded. ${ }^{153}$

A recent report from the Memorial SloanKettering Cancer Center provides evidence of tolerability in immunocompromised patients with pandemic influenza. The patients in this study (age range, 3-80 years; 13 aged $<18$ years) had hematological cancers or solid tumors, and some had also received HSCT; all were positive for pandemic (H1N1) 2009 influenza. In the 43 patients who received oseltamivir at a dose of $75 \mathrm{mg}$ twice daily or the equivalent pediatric dose for 5 days (or for 8 and 17 days in two patients with prolonged shedding or symptoms), treatment was well tolerated and no patients died or required mechanical ventilation. ${ }^{154}$ These findings are supported by a case report on two kidney transplant recipients who had complicated pandemic (H1N1) 2009 influenza infections, in whom prolonged high-dose oseltamivir treatment was well tolerated. ${ }^{155}$ Additionally, no new safety signals were detected in immunocompromised patients exposed to oseltamivir during the 2009 pandemic outbreak. ${ }^{143}$

\section{Elderly Patients}

The pooled analysis of oseltamivir treatment studies mentioned above also included a comparison of $\mathrm{AE}$ incidence between elderly adults aged $\geq 65$ years and adults $<65$ years old; the only differences were that elderly treated patients reported a lower incidence of nausea and vomiting and a higher incidence of dyspepsia. ${ }^{144}$ The safety of oseltamivir was also evaluated in the study of influenza prevention in frail elderly patients by Peters et al., ${ }^{45}$ who found similar safety profiles in the treated and placebo arms, including a relatively low incidence of diarrhea, nausea, and vomiting (all $<5 \%$ ). The evaluation of safety during the 2009 pandemic outbreak did not reveal any new safety signals in 189 elderly patients exposed to oseltamivir. ${ }^{143}$

\section{High-Dose Oral Administration}

Infections with pandemic (H1N1) 2009 and $\mathrm{H} 5 \mathrm{~N} 1$ viruses can give rise to a severe influenza that may not respond to standard antiviral treatment regimens, and the efficacy of extended treatment courses and higher daily doses for influenza treatment is being tested in current clinical trials. An indication of how higher oseltamivir doses might be tolerated is provided by a study in which 194 healthy volunteers received doses of 225 and $450 \mathrm{mg}$ twice daily for 5 days; no evidence of drug accumulation was found, and although nausea, vomiting, and dizziness were more common at the higher doses than standard dose, tolerability was good, with no adverse safety findings. ${ }^{156}$

\section{I.V. Administration}

In January 2010, the EMA CHMP announced that an i.v. presentation of oseltamivir could be used on compassionate use grounds for the treatment of critically ill patients with influenza infection who do not respond to, or cannot be given, neuraminidase inhibitor treatment either orally or by inhalation. As of February 2011, approximately 50 treatment packs had been issued. Roche-sponsored clinical studies are ongoing to establish the safety and tolerability of intravenously administered oseltamivir in infected infants aged 0-1 years (NCT01053663), children aged 1-12 years (NCT01033734), and adults and adolescents aged $\geq 13$ years (NCT01050257). 


\section{PHARMACOECONOMICS}

For the 10 years during which oseltamivir has been available, several studies have been performed to evaluate the pharmacoeconomics of the drug in a range of patient populations. These have mostly measured the costeffectiveness or cost-benefit of oseltamivir as an influenza treatment, compared with interventions such as vaccination and "usual care" regimens (simple analgesics and cough remedies), and occasional reviews of the accumulating evidence base have helped to assess the range of economic benefits that can be achieved. ${ }^{157-159}$ The review of oseltamivir and zanamivir by Lynd et al. ${ }^{158}$ showed that the former was cost-saving from a societal perspective and cost-effective from a healthcareonly perspective, but the authors highlighted the variability in methods and assumptions used in the studies which were reviewed, and how this limited the scope of the conclusions.

The systematic review of 2008 by Postma and colleagues took a different viewpoint, by measuring how cost-effective oseltamivir was relative to usual influenza care regimens. The authors discovered limitations in some of the analytical methods used and the range of assumptions made - for example, most papers that the authors selected failed to describe clearly how altering the disease valuation (willingnessto-pay value) affected the results of the study's analyses, and although most papers in the review assessed economic benefit by using decision models, the important assumptions behind the models varied widely, such as the expected rate of confirmed influenza in individuals presenting with ILI, and the amount of work-time lost to illness. Nevertheless, the authors found that oseltamivir treatment was cost-effective relative to usual care in the four population groups studied (adults and adolescents, children
$>15$ years of age, elderly patients, and those in high-risk groups). ${ }^{159}$

Decision models continue to be the basis for economic analysis in some more recent studies. One group who assessed cost-effectiveness of oseltamivir used as PEP from the United Kingdom (UK) healthcare payer's perspective showed that the intervention would be costeffective compared with a usual-care treatment strategy if SARs in household contacts were $\geq 8 \%$. ${ }^{160}$ Other groups have examined costeffectiveness in the treatment setting. An analysis that compared oseltamivir treatment for ILI with usual care in the Netherlands focused on patients at elevated risk of serious complications from influenza infection; the study found that, from the societal perspective, oseltamivir was cost-saving for chronically ill adults (of any age) and cost-effective (€1759 per life-year gained) for otherwise healthy elderly patients. ${ }^{161}$ A US group used a decision-analysis model to confirm the findings of the 2008 Postma et al. ${ }^{159}$ review, ie, that treatment of ILI with oseltamivir was costeffective compared with usual care in highrisk adults, healthy adults, elderly adults, and children, from both the societal and healthcare payer perspectives. ${ }^{162}$ Notably, the authors analysis assumed that treatment would be ineffective if given later than 48 hours after symptom onset or in individuals infected with virus resistant to oseltamivir. A recent study on the cost-effectiveness of oseltamivir treatment in Japan also investigated the effects of emerging resistance on economic benefit. The authors found that, from a healthcare payer's perspective, the cost per quality-adjusted life year (QALY) gained was US\$3320 and, from a societal perspective (considering the cost of lost work time), oseltamivir was dominant; however, if the incidence of resistant virus exceeded $27 \%$, oseltamivir was no longer 
dominant. Allowing for the emergence of resistance and other uncertainties, the authors calculated an $80 \%$ probability that the drug would be cost-effective at a willingness-to-pay level of US\$50,000/year. ${ }^{163}$

Most recently, the economic benefits of antiviral therapies have been evaluated in the setting of pandemic mitigation. Before and during the 2009 pandemic, pandemic response strategies attracted much attention, but as with the simpler cost-effectiveness question above, the relative benefits of each mitigation measure depended closely on assumptions about, for example, the virulence of the pandemic virus and how quickly and widely the pandemic would spread. The most commonly evaluated mitigation measures to date are treatment and/or prophylaxis with stockpiled antivirals, vaccination, school closures, and travel restrictions. In a review of 12 studies on this topic by Lugner and Postma, ${ }^{164}$ five studies that specifically evaluated stockpiling of antiviral drugs showed that this measure would be cost-effective assuming it was used to treat symptomatic individuals, and could also be cost-effective if used for prophylaxis in some scenarios. This review also discussed the merits of dynamic models, ie, those that measure disease transmission, in relation to static or decision-tree models for valuation assessments, and concluded that dynamic models produce a more valid estimate of cost-effectiveness. One of the studies reviewed by Lugner and Postma that used this approach (a stochastic transmission model) to evaluate a range of mitigation measures, fully accounting for the cost of stockpiling and delivery of antivirals, was the analysis by Sander et al. ${ }^{165}$ This study demonstrated that full targeted antiviral prophylaxis (FTAP), ie, coverage of household contacts as well as $60 \%$ of work and school contacts, was the most effective single strategy, slightly outperforming pre-vaccination and more restricted antiviral prophylaxis measures - FTAP reduced the number of cases by $54 \%$ at a cost of $\$ 127$ to society. ${ }^{165}$

\section{CONCLUSIONS}

In the period of just over 10 years since oseltamivir was introduced, it has proved to be an effective, safe, and valuable antiviral agent for the management of influenza infections in many settings. Early clinical trials in patients with mild disease showed that treatment could lessen symptom severity, shorten illness duration, and reduce the risk of complications, and that preventative use could protect against illness, but recent studies in seriously ill patients have demonstrated its value in avoiding more severe outcomes, including death; the latter evidence includes experience in avian H5N1 influenza and pandemic (H1N1) 2009 influenza. Natural resistance to oseltamivir in the H1N1 seasonal virus strain emerged in 2007, but this strain virtually disappeared after the arrival of the novel H1N1 strain that caused the 2009 pandemic. Drug-induced resistance remains very rare, and oseltamivir has proved to be well tolerated by all population groups.

New research now under way will provide more information on the efficacy and safety profile of oseltamivir in vulnerable population groups, such as very young infants and immunocompromised patients, as well as in severely ill patients in the ICU setting. Some studies will investigate resistance in more detail, and others will assess the effectiveness of highdose treatment regimens, particularly in patients with avian $\mathrm{H} 5 \mathrm{~N} 1$ influenza.

Despite WHO having declared in August 2010 that the 2009 influenza pandemic outbreak has ended and the post-pandemic stage has started, influenza will remain a serious challenge for 
healthcare professionals. New emergencies are inevitable, including the possible evolution of avian $\mathrm{H} 5 \mathrm{~N} 1$ and other influenza viruses into strains with more efficient human-to-human transmissibility. The threat from influenza has evolved in the 10 years since the arrival of oseltamivir, and it is certain that the threat will continue to evolve in the future.

\section{ACKNOWLEDGMENTS}

Support for third-party writing assistance for this manuscript was provided by F. Hoffmann-La Roche Ltd. All authors are employees of Roche. James Smith, Regina Dutkowski, Barbara Donner, and Martina Wollenhaupt also have stock ownership options in Roche. All authors contributed to the design, conduct, analysis, and/or interpretation of at least one of the investigations reported herein, some of which were supported by Roche. All authors participated in the preparation, review, and approval of this article. Support for thirdparty writing assisting for this manuscript was provided by Roche. James Smith is the guarantor for this article, and takes responsibility for the integrity of the work as a whole.

Open Access. This article is distributed under the terms of the Creative Commons Attribution Noncommercial License which permits any noncommercial use, distribution, and reproduction in any medium, provided the original author(s) and source are credited.

\section{REFERENCES}

1. Centers for Disease Control and Prevention (CDC). Key facts about influenza (flu) and flu vaccine. Revised 3 June 2010. Available at: http:// www.cdc.gov/flu/keyfacts.htm. Last accessed September 2, 2010.

2. Thompson WW, Shay DK, Weintraub E, et al. Mortality associated with influenza and respiratory syncytial virus in the United States. JAMA. 2003;289:179-186.
3. Thompson WW, Shay DK, Weintraub E, et al. Influenza-associated hospitalizations in the United States. JAMA. 2004;292:1333-1340.

4. Writing Committee of the WHO Consultation on Clinical Aspects of Pandemic (H1N1) 2009 Influenza, Bautista E, Chotpitayasunondh $\mathrm{T}$, et al. Clinical aspects of pandemic 2009 influenza A (H1N1) virus infection. $N$ Engl J Med. 2010;362:1708-1719.

5. World Health Organization (WHO). Cumulative number of confirmed human cases of avian influenza $\mathrm{A} /(\mathrm{H} 5 \mathrm{~N} 1)$ reported to WHO: 19 November 2010. Available at: http://www.who. int/csr/disease/avian_influenza/country/cases_ table_2010_11_19/en/index.html. Last accessed September 1, 2010.

6. Tamiflu SmPC. Tamiflu Summary of Product Characteristics. 2011. Available at: http://www. medicines.org.uk/emc/. Last accessed September 2, 2010.

7. Tamiflu PI. Tamiflu Prescribing Information. 2011. Available at: http://www.accessdata.fda.gov/scripts/ cder/drugsatfda/index.cfm?fuseaction=Search.

Search_Drug_Name. Last accessed September 2, 2010.

8. Moscona A. Neuraminidase inhibitors for influenza. N Engl J Med. 2005;353:1363-1373.

9. World Health Organization (WHO). WHO guidelines for pharmacological management of pandemic influenza A(H1N1) 2009 and other influenza viruses. Revised February 2010. Available at: http://www.who.int/csr/resources/publications/ swineflu/h1n1_use_antivirals_20090820/en/index. html. Last accessed September 1, 2010.

10. Health Protection Agency. Pharmacologicial treatment and prophylaxis of influenza. Version 1.7. Available at: http://www.hpa.org.uk/web/ HPAwebFile/HPAweb_C/1287147812045. Last accessed January 12, 2011.

11. World Health Organization (WHO). Clinical management of human infection with avian influenza A (H5N1) virus. 15 August 2007. Available at: http://www.who.int/csr/disease/avian_influenza/ guidelines/ClinicalManagement07.pdf. Last accessed September 1, 2010.

12. Adisasmito W, Chan PK, Lee N, et al. Effectiveness of antiviral treatment in human influenza A(H5N1) infections: analysis of a Global Patient Registry. J Infect Dis. 2010;202:1154-1160. 
13. He G, Massarella J, Ward P. Clinical pharmacokinetics of the prodrug oseltamivir and its active metabolite Ro 64-0802. Clin Pharmacokinet. 1999;37:471-484.

14. Roberts NA, Wiltshire HR, Mendel DB, Webster RG. Oseltamivir carboxylate is effective against all subtypes of influenza neuraminidase. ASM Biodefense Research Meeting. Baltimore, Maryland, USA. March 9-12, 2003. Abstract.

15. World Health Organization (WHO). Update on oseltamivir-resistant pandemic (H1N1) 2009 influenza virus: January 2010. Wkly Epidemiol Rec. 2010;85:37-48.

16. Stoner TD, Krauss S, DuBois RM, et al. Antiviral susceptibility of avian and swine influenza virus of the N1 neuraminidase subtype. J Virol. 2010;84:9800-9809.

17. Kurowski M, Oo C, Wiltshire H, Barrett J. Oseltamivir distributes to influenza virus replication sites in the middle ear and sinuses. Clin Drug Invest. 2004;24:49-53.

18. Jhee SS, Yen M, Ereshefsky L, et al. Low penetration of oseltamivir and its carboxylate into cerebrospinal fluid in healthy Japanese and Caucasian volunteers. Antimicrob Agents Chemother. 2008;52:3687-3693.

19. Abe M, Smith J, Urae A, et al. Pharmacokinetics of oseltamivir in young and very elderly subjects. Ann Pharmacother. 2006;40:1724-1730.

20. Schentag JJ, Hill G, Chu T, Rayner CR. Similarity in pharmacokinetics of oseltamivir and oseltamivir carboxylate in Japanese and Caucasian subjects. J Clin Pharmacol. 2007;47:689-696.

21. Oo C, Barrett J, Hill G, et al. Pharmacokinetics and dosage recommendations for an oseltamivir oral suspension for the treatment of influenza in children. Paediatr Drugs. 2001;3:229-236.

22. Strolin Benedetti M, Whomsley R, Baltes EL. Differences in absorption, distribution, metabolism and excretion of xenobiotics between the paediatric and adult populations. Expert Opin Drug Metab Toxicol. 2005;1:447-471.

23. Vogt BA, Davis ID, Avner ED. The kidney. In: Klaus MH, Fanaroff AA, editors. Care of the highrisk neonate. 5th Edition. Pennsylvania: Saunders; 2001:426-427.
24. Acosta EP, Kimberlin DW. Determination of appropriate dosing of influenza drugs in pediatric patients. Clin Pharmacol Ther. 2010;88:704-707.

25. Acosta EP, Jester P, Gal P, et al. Oseltamivir dosing for influenza infection in premature neonates. $\mathrm{J}$ Infect Dis. 2010;202:563-566.

26. Worley KC, Roberts SW, Bawdon RE. The metabolism and transplacental transfer of oseltamivir in the ex vivo human model. Infect Dis Obstet Gynecol. 2008;2008:927574.

27. Wentges-van HN, van Eijkeren M, van der Laan JW. Oseltamivir and breastfeeding. Int J Infect Dis. 2008;12:451.

28. Robson R, Buttimore A, Lynn K, Brewster M, Ward P. The pharmacokinetics and tolerability of oseltamivir suspension in patients on haemodialysis and continuous ambulatory peritoneal dialysis. Nephrol Dial Transplant. 2006;21:2556-2562.

29. Snell P, Dave N, Wilson K, et al. Lack of effect of moderate hepatic impairment on the pharmacokinetics of oral oseltamivir and its metabolite oseltamivir carboxylate. $\mathrm{Br} \mathrm{J}$ Clin Pharmacol. 2005;59:598-601.

30. Morrison D, Roy S, Rayner C, et al. A randomized, crossover study to evaluate the pharmacokinetics of amantadine and oseltamivir administered alone and in combination. PLOS ONE. 2007;2:e1305.

31. Davies BE, Cirrincione-Dall G, Ballester-Sanchis RM, Navarro MT, Brennen B. Pharmacokinetics and safety of co-administered oseltamivir and rimantadine in healthy subjects: an open-label, multiple-dose, randomised, crossover study. XII International Symposium on Respiratory Viral Infections. Taipei, Taiwan. March 11-14, 2010. Abstract.

32. Oo C, Barrett J, Dorr A, Liu B, Ward P. Lack of pharmacokinetic interaction between the oral anti-influenza prodrug oseltamivir and aspirin. Antimicrob Agents Chemother. 2002;46:1993-1995.

33. Snell P, Oo C, Dorr A, Barrett J. Lack of pharmacokinetic interaction between the oral anti-influenza neuraminidase inhibitor prodrug oseltamivir and antacids. Br J Clin Pharmacol. 2002;54:372-377.

34. Hill G, Cihlar T, Oo C, et al. The anti-influenza drug oseltamivir exhibits low potential to induce pharmacokinetic drug interactions via renal secretion-correlation of in vivo and in vitro studies. Drug Metab Dispos. 2002;30:13-19. 
35. Davies BE, Aceves Baldo P, Brewster M. Effect of oseltamivir on anticoagulation: a crossover study in patients stabilized on warfarin. 49th Interscience Conference on Antimicrobial Agents and Chemotherapy. San Francisco, CA. September 12-15, 2009. Abstract.

36. Aoki F, Lam H, Jeffrey JR, Sitar DS. Oseltamivir does not interact pharmacokinetically with cyclosporine, mycophenolate or tacrolimus in renal transplant patients. Annual Meeting of the Infectious Disease Society of America. San Francisco, CA, USA. October 6-9, 2005. Abstract.

37. Holodniy M, Penzak SR, Straight TM, et al. Pharmacokinetics and tolerability of oseltamivir combined with probenecid. Antimicrob Agents Chemother. 2008;52:3013-3021.

38. Rayner CR, Chanu P, Gieschke R, Boak LM, Jonsson EN. Population pharmacokinetics of oseltamivir when coadministered with probenecid. J Clin Pharmacol. 2008;48:935-947.

39. Treanor JJ, Hayden FG, Vrooman PS, et al. Efficacy and safety of the oral neuraminidase inhibitor oseltamivir in treating acute influenza: a randomized controlled trial. US Oral Neuraminidase Study Group. JAMA. 2000;283:1016-1024.

40. Nicholson KG, Aoki FY, Osterhaus AD, et al. Efficacy and safety of oseltamivir in treatment of acute influenza: a randomised controlled trial. Neuraminidase Inhibitor Flu Treatment Investigator Group. Lancet. 2000;355:1845-1850.

41. Kaiser L, Wat C, Mills T, et al. Impact of oseltamivir treatment on influenza-related lower respiratory tract complications and hospitalizations. Arch Intern Med. 2003;163:1667-1672.

42. Welliver R, Monto AS, Carewicz O, et al. Effectiveness of oseltamivir in preventing influenza in household contacts: a randomized controlled trial. JAMA. 2001;285:748-754.

43. Hayden FG, Belshe R, Villanueva C, et al. Management of influenza in households: a prospective, randomized comparison of oseltamivir treatment with or without postexposure prophylaxis. J Infect Dis. 2004;189:440-449.

44. Hayden FG, Atmar RL, Schilling M, et al. Use of the selective oral neuraminidase inhibitor oseltamivir to prevent influenza. N Engl J Med. 1999;341:1336-1343.
45. Peters Jr. PH, Gravenstein S, Norwood P, et al. Long-term use of oseltamivir for the prophylaxis of influenza in a vaccinated frail older population. J Am Geriatr Soc. 2001;49:1025-1031.

46. Whitley RJ, Hayden FG, Reisinger KS, et al. Oral oseltamivir treatment of influenza in children. Pediatr Infect Dis J. 2001;20:127-133.

47. Winther B, Block SL, Reisinger K, Dutkowski R. Impact of oseltamivir treatment on the incidence and course of acute otitis media in children with influenza. Int J Pediatr Otorhinolaryngol. 2010;74:684-688.

48. Reisinger K, Marcadis I, Cupelli LA, Shu D. Oseltamivir for prevention of seasonal influenza in children. Options for the Control of Influenza VI. Toronto, Canada. June 17-23, 2007. Abstract.

49. Sugaya N, Mitamura K, Yamazaki M, et al. Lower clinical effectiveness of oseltamivir against influenza B contrasted with influenza A infection in children. Clin Infect Dis. 2007;44:197-202.

50. Sugaya N, Tamura D, Yamazaki M, et al. Comparison of the clinical effectiveness of oseltamivir and zanamivir against influenza virus infection in children. Clin Infect Dis. 2008;47:339-345.

51. Barr CE, Schulman K, Iacuzio D, Bradley JS. Effect of oseltamivir on the risk of pneumonia and use of health care services in children with clinically diagnosed influenza. Curr Med Res Opin. 2007;23:523-531.

52. Piedra PA, Schulman KL, Blumentals WA. Effects of oseltamivir on influenza-related complications in children with chronic medical conditions. Pediatrics. 2009;124:170-178.

53. Johnston SL, Ferrero F, Garcia ML, Dutkowski R. Oral oseltamivir improves pulmonary function and reduces exacerbation frequency for influenzainfected children with asthma. Pediatr Infect Dis J. 2005;24:225-232.

54. Lin JT, Yu XZ, Cui DJ, et al. A multicentre, randomized, controlled trial of oseltamivir in the treatment of influenza in a high-risk Chinese population. Curr Med Res Opin. 2006;22:75-82.

55. Chemaly RF, Ghosh S, Bodey GP, et al. Respiratory viral infections in adults with hematologic malignancies and human stem cell transplantation recipients: a retrospective study at a major cancer center. Medicine (Baltimore). 2006;85:278-287. 
56. Peters PH, Moscona A, Schulman KL, Barr CE. Study of the impact of oseltamivir on the risk for pneumonia and other outcomes of influenza, 2000-2005. Medscape J Med. 2008;10:131.

57. McGeer A, Green KA, Plevneshi A, et al. Antiviral therapy and outcomes of influenza requiring hospitalization in Ontario, Canada. Clin Infect Dis. 2007;45:1568-1575.

58. Lee N, Choi KW, Chan PK, et al. Outcomes of adults hospitalised with severe influenza. Thorax. 2010;65:510-515.

59. Dutkowski R. Oseltamivir in seasonal influenza: cumulative experience in low- and high-risk patients. J Antimicrob Chemother. 2010;65(Suppl. 2):ii11-ii24.

60. Ward P, Small I, Smith J, Suter P, Dutkowski R. Oseltamivir (Tamiflu) and its potential for use in the event of an influenza pandemic. J Antimicrob Chemother. 2005;55(Suppl. 1):i5-i21.

61. Matheson NJ, Harnden AR, Perera R, Sheikh A, Symmonds-Abrahams M. Neuraminidase inhibitors for preventing and treating influenza in children. Cochrane Database Syst Rev. 2007;CD002744.

62. Jefferson T, Jones M, Doshi P, Del Mar C. Neuraminidase inhibitors for preventing and treating influenza in healthy adults: systematic review and meta-analysis. BMJ. 2009;339:b5106.

63. Ruf BR, Szucs T. Reducing the burden of influenzaassociated complications with antiviral therapy. Infection. 2009;37:186-196.

64. Hernan MA, Lipsitch M. Oseltamivir and risk of lower respiratory tract complications in patients with flu symptoms: a meta-analysis of eleven randomized clinical trials. Clin Infect Dis. 2011;53:277-279.

65. Aoki FY, Macleod MD, Paggiaro P, et al. Early administration of oral oseltamivir increases the benefits of influenza treatment. J Antimicrob Chemother. 2003;51:123-129.

66. Kawai N, Ikematsu H, Iwaki N, et al. A comparison of the effectiveness of oseltamivir for the treatment of influenza A and influenza B: a Japanese multicenter study of the 2003-2004 and 2004-2005 influenza seasons. Clin Infect Dis. 2006;43:439-444.

67. Heinonen S, Silvennoinen $H$, Lehtinen $P$, et al. Early oseltamivir treatment of influenza in children 1-3 years of age: a randomized controlled trial. Clin Infect Dis. 2010;51:887-894.
68. Writing Committee of the Second World Health Organization Consultationon Clinical Aspects of Human Infection with Avian Influenza A (H5N1) Virus. Update on avian influenza A (H5N1) virus infection in humans. N Engl J Med. 2008;358:261-273.

69. Gambotto A, Barratt-Boyes SM, de Jong MD, Neumann G, Kawaoka Y. Human infection with highly pathogenic H5N1 influenza virus. Lancet. 2008;371:1464-1475.

70. Kandun IN, Tresnaningsih E, Purba WH, et al. Factors associated with case fatality of human H5N1 virus infections in Indonesia: a case series. Lancet. 2008;372:744-749.

71. Liem NT, Tung CV, Hien ND, et al. Clinical features of human influenza A (H5N1) infection in Vietnam: 2004-2006. Clin Infect Dis. 2009;48:1639-1646.

72. Hien ND, Ha NH, Van NT, et al. Human infection with highly pathogenic avian influenza virus (H5N1) in northern Vietnam, 2004-2005. Emerg Infect Dis. 2009;15:19-23.

73. Smith JR. Oseltamivir in human avian influenza infection. J Antimicrob Chemother. 2010;65(Suppl. 2):ii25-ii33.

74. World Health Organization (WHO). Pandemic (H1N1) 2009 - update 112. 6 August 2010. Available at: http://www.who.int/csr/don/2010_08_06/en/ index.html. Last accessed September 1, 2010.

75. Li IW, Hung IF, To KK, et al. The natural viral load profile of patients with pandemic swine-origin influenza A H1N1 2009 (pH1N1) and the effect of oseltamivir treatment. Chest. 2010;137:759-768.

76. Cao B, Li XW, Mao Y, et al. Clinical features of the initial cases of 2009 pandemic influenza A (H1N1) virus infection in China. N Engl J Med. 2009;361:2507-2517.

77. Ling LM, Chow AL, Lye DC, et al. Effects of early oseltamivir therapy on viral shedding in 2009 pandemic influenza A (H1N1) virus infection. Clin Infect Dis. 2010;50:963-969.

78. Hien TT, Boni MF, Bryant JE, et al. Early pandemic influenza (2009 H1N1) in Ho Chi Minh City, Vietnam: a clinical virological and epidemiological analysis. PLoS Med. 2010;7:e1000277.

79. Lee N, Chan PK, Hui DS, et al. Viral loads and duration of viral shedding in adult patients hospitalized with influenza. J Infect Dis. 2009;200:492-500. 
80. Jain S, Kamimoto L, Bramley AM, et al. Hospitalized Patients with 2009 H1N1 Influenza in the United States, April-June 2009. N Engl J Med. 2009;361:1935-1944.

81. Farias JA, Fernandez A, Monteverde E, et al. Critically ill infants and children with influenza A (H1N1) in pediatric intensive care units in Argentina. Intensive Care Med. 2010;36:1015-1022.

82. Dominguez-Cherit G, Lapinsky SE, Macias AE, et al. Critically ill patients with 2009 influenza A(H1N1) in Mexico. JAMA. 2009;302:1880-1887.

83. Chien YS, Su CP, Tsai HT, et al. Predictors and outcomes of respiratory failure among hospitalized pneumonia patients with $2009 \mathrm{H} 1 \mathrm{~N} 1$ influenza in Taiwan. J Infect. 2010;60:168-174.

84. Centers for Disease Control and Prevention. Patients hospitalized with 2009 pandemic influenza A (H1N1) - New York City, May 2009. MMWR Morb Mortal Wkly Rep. 2010;58:14361440.

85. Campbell CN, Mytton OT, McLean EM, et al. Hospitalization in two waves of pandemic influenza $\mathrm{A}(\mathrm{H} 1 \mathrm{N1})$ in England. Epidemiol Infect. 2011;139:1560-1569.

86. Lee $\mathrm{EH}, \mathrm{Wu} \mathrm{C}$, Lee EU, et al. Fatalities associated with the 2009 H1N1 influenza A virus in New York city. Clin Infect Dis. 2010;50:1498-1504.

87. Louie JK, Acosta M, Jamieson DJ, Honein MA. Severe 2009 H1N1 influenza in pregnant and postpartum women in California. N Engl J Med. 2010;362:27-35.

88. Siston AM, Rasmussen SA, Honein MA, et al. Pandemic 2009 influenza $\mathrm{A}(\mathrm{H} 1 \mathrm{~N} 1)$ virus illness among pregnant women in the United States. JAMA. 2010;303:1517-1525.

89. Creanga AA, Johnson TF, Graitcer SB, et al. Severity of 2009 pandemic influenza A (H1N1) virus infection in pregnant women. Obstet Gynecol. 2010;115:717-726.

90. Kumar D, Michaels MG, Morris MI, et al. Outcomes from pandemic influenza A H1N1 infection in recipients of solid-organ transplants: a multicentre cohort study. Lancet Infect Dis. 2010;10:521-526.

91. Louie JK, Acosta M, Winter $\mathrm{K}$, et al. Factors associated with death or hospitalization due to pandemic 2009 influenza $\mathrm{A}(\mathrm{H} 1 \mathrm{~N} 1)$ infection in California. JAMA. 2009;302:1896-1902.
92. Torres JP, O'Ryan M, Herve B, et al. Impact of the novel influenza A (H1N1) during the 2009 autumn-winter season in a large hospital setting in Santiago, Chile. Clin Infect Dis. 2010;50:860-868.

93. Institut de Veille Sanitaire (InVS). Benefit of early antiviral therapy in reducing the severity and mortality of influenza A (H1N1) 2009: data obtained from serious infection monitoring [French]. Available at: http://www.invs.sante.fr/ surveillance/grippe_dossier/docs_professionnels/ antiviraux_grippe_a_h1n1_211209.pdf. Last accessed February 19, 2010.

94. Zarychanski R, Stuart TL, Kumar A, et al. Correlates of severe disease in patients with 2009 pandemic influenza (H1N1) virus infection. CMAJ. 2010;182:257-264.

95. Lee VJ, Yap J, Cook AR, et al. Oseltamivir ring prophylaxis for containment of $2009 \mathrm{H} 1 \mathrm{~N} 1$ influenza outbreaks. N Engl J Med. 2010;362:2166-2174.

96. Komiya N, Gu Y, Kamiya H, et al. Household transmission of pandemic 2009 influenza a (H1N1) virus in Osaka, Japan in May 2009. J Infect. 2010;61:284-288.

97. Leung YH, Li MP, Chuang SK. A school outbreak of pandemic (H1N1) 2009 infection: assessment of secondary household transmission and the protective role of oseltamivir. Epidemiol Infect. 2011;139:41-44.

98. Aoki FY, Boivin G, Roberts N. Influenza virus susceptibility and resistance to oseltamivir. Antivir Ther. 2007;12:603-616.

99. Dharan NJ, Gubareva LV, Meyer JJ, et al. Infections with oseltamivir-resistant influenza $\mathrm{A}(\mathrm{H} 1 \mathrm{~N} 1)$ virus in the United States. JAMA. 2009;301:1034-1041.

100. Hauge SH, Dudman S, Borgen K, Lackenby A, Hungnes O. Oseltamivir-resistant influenza viruses A (H1N1), Norway, 2007-08. Emerg Infect Dis. 2009;15:155-162.

101. Kiso M, Mitamura K, Sakai-Tagawa Y, et al. Resistant influenza A viruses in children treated with oseltamivir: descriptive study. Lancet. 2004;364:759-765.

102. Stephenson I, Democratis J, Lackenby A, et al. Neuraminidase inhibitor resistance after oseltamivir treatment of acute influenza A and B in children. Clin Infect Dis. 2009;48:389-396. 
103. Toovey S, Rayner C, Prinssen E, et al. Assessment of neuropsychiatric adverse events in influenza patients treated with oseltamivir: a comprehensive review. Drug Saf. 2008;31:1097-1114.

104. NISN. Monitoring of neuraminidase inhibitor resistance among clinical influenza virus isolates in Japan during the 2003-2006 influenza seasons. Wkly Epidemiol Rec. 2007;82:149-150.

105. Monto AS, McKimm-Breschkin JL, Macken C, et al. Detection of influenza viruses resistant to neuraminidase inhibitors in global surveillance during the first 3 years of their use. Antimicrob Agents Chemother. 2006;50:2395-2402.

106. Sheu TG, Deyde VM, Okomo-Adhiambo M, et al. Surveillance for neuraminidase inhibitor resistance among human influenza $\mathrm{A}$ and $\mathrm{B}$ viruses circulating worldwide from 2004 to 2008. Antimicrob Agents Chemother. 2008;52:3284-3292.

107. Meijer A, Lackenby A, Hungnes O, et al. Oseltamivirresistant influenza virus A (H1N1), Europe, 2007-08 Season. Emerg Infect Dis. 2009;15:552-560.

108. Kramarz P, Monnet D, Nicoll A, Yilmaz C, Ciancio B. Use of oseltamivir in 12 European countries between 2002 and 2007 - lack of association with the appearance of oseltamivirresistant influenza $\mathrm{A}(\mathrm{H} 1 \mathrm{~N} 1)$ viruses. Euro Surveill. 2009;14:pii19112.

109. Goddard N, Zucs P, Ciancio B, et al. Start of the influenza season 2008-9 in Europe increasing influenza activity moving from West to East dominated by $\mathrm{A}(\mathrm{H} 3 \mathrm{~N} 2)$. Euro Surveill. 2009;14:pii:19097.

110. Centers for Disease Control and Prevention (CDC). Update: influenza activity - United States, September 28, 2008 - April 4, 2009, and composition of the 2009/10 influenza vaccine. MMWR Morb Mortal Wkly Rep. 2009;58:369-374.

111. Rameix-Welti MA, Enouf V, Cuvelier F, Jeannin $\mathrm{P}$, van der Werf S. Enzymatic properties of the neuraminidase of seasonal H1N1 influenza viruses provide insights for the emergence of natural resistance to oseltamivir. PLoS Pathog. 2008;4:e1000103.

112. Bloom JD, Gong LI, Baltimore D. Permissive secondary mutations enable the evolution of influenza oseltamivir resistance. Science. 2010;328:1272-1275.
113. Hurt AC, Selleck P, Komadina N, et al. Susceptibility of highly pathogenic A (H5N1) avian influenza viruses to the neuraminidase inhibitors and adamantanes. Antiviral Res. 2007;73:228-231.

114. Hill AW, Guralnick RP, Wilson MJ, Habib F, Janies D. Evolution of drug resistance in multiple distinct lineages of H5N1 avian influenza. Infect Genet Evol. 2009;9:169-178.

115. de Jong MD, Tran TT, Truong HK, et al. Oseltamivir resistance during treatment of influenza A (H5N1) infection. N Engl J Med. 2005;353:2667-2672.

116. Le QM, Kiso M, Someya K, et al. Avian flu: isolation of drug-resistant $\mathrm{H} 5 \mathrm{~N} 1$ virus. Nature. 2005;437:1108.

117. Earhart KC, Elsayed NM, Saad MD, et al. Oseltamivir resistance mutation N294S in human influenza A (H5N1) virus in Egypt. J Infect Public Health. 2009;2:74-80.

118. World Health Organization (WHO). Weekly virological update. 26 August 2010. Available at: http://www.who.int/csr/disease/swineflu/notes/ briefing_20091202/en/index.html. Last accessed September 2, 2010.

119. Garten RJ, Davis CT, Russell CA, et al. Antigenic and genetic characteristics of swine-origin 2009 A(H1N1) influenza viruses circulating in humans. Science. 2009;325:197-201.

120. World Health Organization (WHO). Update on oseltamivir resistance in influenza A(H1N1)2009 viruses. 10 August 2011. Available at: http://www.who.int/influenza/surveillance_ monitoring/updates/2011_08_12_weekly_web_ update_oseltamivir_resistance.pdf. Last accessed January 12, 2011.

121. Hayden FG. Antiviral resistance in influenza viruses: clinical and epidemiological aspects. In: Mayers DL, editor. Antimicrobial Drug Resistance. New York: Humana Press; 2009:1011-1034.

122. Harvala H, Gunson R, Simmonds $P$, et al. The emergence of oseltamivir-resistant pandemic influenza A(H1N1) 2009 virus amongst hospitalised immunocompromised patients in Scotland, November-December, 2009. Euro Surveill. 2010;15:pii19536.

123. Tramontana AR, George B, Hurt AC, et al. Oseltamivir resistance in adult oncology and hematology patients infected with pandemic (H1N1) 2009 virus, Australia. Emerg Infect Dis. 2010;16:1068-1075. 
124. Rousset D, Le Goff J, Abou-Jaoude G. Emergence of successive mutations in the neuraminidase of the pandemic H1N1 virus respectively associated with oseltamivir resistance and reduced susceptibility to both oseltamivir and zanamivir under treatment with neuraminidase inhibitors. Options for the Control of Influenza. Hong Kong. September 3-7, 2010. Abstract.

125. van der Vries E, Stelma FF, Boucher CA. Emergence of a multidrug-resistant pandemic influenza A (H1N1) virus. $\mathrm{N}$ Engl J Med. 2010;363:1381-1382.

126. World Health Organization. Weekly update on oseltamivir resistance to influenza A (H1N1) 2009 viruses. Available at: http://www.who.int/csr/ disease/swineflu/oseltamivirresistant20100820.pdf. Last accessed September 1, 2010.

127. Baz M, Abed Y, Papenburg J, et al. Emergence of oseltamivir-resistant pandemic H1N1 virus during prophylaxis. N Engl J Med. 2009;361:2296-2297.

128. Centers for Disease Control and Prevention. Oseltamivir-resistant 2009 pandemic influenza A (H1N1) virus infection in two summer campers receiving prophylaxis - North Carolina, 2009. MMWR Morb Mortal Wkly Rep. 2009;58:969-972.

129. World Health Organization (WHO). Oseltamivirresistant pandemic (H1N1) 2009 influenza virus, October 2009. Wkly Epidemiol Rec. 2009;84:453-459.

130. Hamelin ME, Baz M, Abed Y, et al. Oseltamivirresistant pandemic $\mathrm{A} / \mathrm{H} 1 \mathrm{~N} 1$ virus is as virulent as its wild-type counterpart in mice and ferrets. PLoS Pathog. 2010;6:e1001015.

131. Duan S, Boltz DA, Seiler P, et al. Oseltamivirresistant pandemic H1N1/2009 influenza virus possesses lower transmissibility and fitness in ferrets. PLoS Pathog. 2010;6:e1001022.

132. Kiso M, Shinya K, Shimojima M, et al. Characterization of oseltamivir-resistant 2009 H1N1 pandemic influenza A viruses. PLoS Pathog. 2010;6:e1001079.

133. Smith EV, Pynn MC, Blackford S, Leopold DJ. Stevens-Johnson syndrome secondary to oseltamivir (Tamiflu). Br J Gen Pract. 2010;60:133-134.

134. Wells Q, Hardin B, Raj SR, Darbar D. Sotalolinduced torsades de pointes precipitated during treatment with oseltamivir for H1N1 influenza. Heart Rhythm. 2010;7:1454-1457.
135. Karplus R, Sanset S, Zaidenstein R, Schneider D, Berkovitch M. Suspected oseltamivir-induced bradycardia. Int J Infect Dis. 2010;14(Suppl. 3): e374-e375.

136. Casscells SW, Granger E, Kress AM, Linton A, Madjid M. Use of oseltamivir after influenza infection is associated with reduced incidence of recurrent adverse cardiovascular outcomes among military health system beneficiaries with prior cardiovascular disease. Circulation. 2009;2:108-115.

137. Madjid M, Curkendall S, Blumentals WA. The influence of oseltamivir on the risk of stroke after influenza infection. Cardiology. 2009;113:98-107.

138. Okabe N, Yamashita K, Taniguchi K, Inouye S. Influenza surveillance system of Japan and acute encephalitis and encephalopathy in the influenza season. Pediatr Int. 2000;42:187-191.

139. Kasai T, Togashi T, Morishima T. Encephalopathy associated with influenza epidemics. Lancet. 2000;355:1558-1559.

140. Morishima T, Togashi T, Yokota S, et al. Encephalitis and encephalopathy associated with an influenza epidemic in Japan. Clin Infect Dis. 2002;35:512-517.

141. United States Food and Drug Administration (FDA). Meeting of the FDA Pediatric Advisory Committee, 16 November 2006. Available at: http://www.fda.gov/OHRMS/DOCKETS/ac/oc06. htm. Last accessed July 3, 2008.

142. Casscells SW, Granger E, Kress AM, Linton A. The association between oseltamivir use and adverse neuropsychiatric outcomes among TRICARE beneficiaries, ages 1 through 21 years diagnosed with influenza. Int $\mathrm{J}$ Adolesc Med Health. 2009;21:79-89.

143. Donner B, Bader-Weder S, Schwarz R, et al. Safety profile of oseltamivir during the 2009 influenza pandemic. Options for the Control of Influenza, Hong Kong SAR, China. September 3-7, 2010. Abstract.

144. Dutkowski R, Thakrar B, Froehlich E, et al. Safety and pharmacology of oseltamivir in clinical use. Drug Saf. 2003;26:787-801.

145. Reisinger K, Cupelli LA, and Shu D. Seasonal prophylaxis of influenza with oseltamivir in children. 5th Annual Meeting of the World Society for Paediatric Infectious Diseases (WSPID). Bangkok, Thailand. November 15-18, 2007. Abstract. 
146. European Medicines Evaluation Agency (EMEA). Assessment report for Tamiflu. London, 24 September 2009. Available at: http://www.emea. europa.eu/docs/en_GB/document_library/EPAR_-_ Assessment_Report_-_Variation/human/000402/ WC500033109.pdf. Last accessed September 2, 2010.

147. Centers for Disease Control and Prevention (CDC). Interim guidance on antiviral recommendations for patients with novel influenza A (H1N1) virus infection and their close contacts. Updated 7 December 2009. Available at: http://www.cdc.gov/ h1n1flu/recommendations.htm. Last accessed September 1, 2010.

148. Siedler K, Skopnik H. Oseltamivir for treatment of influenza in infants less than one year: a retrospective analysis. Pediatr Infect Dis J. 2010;29:495-498.

149. European Medicines Evaluation Agency (EMEA). Opinion of the Committee for Medicinal Products for Human Use pursuant to Article 5(3) of Regulation (EC) No.726/2004, on novel influenza (H1N1) outbreak; Tamiflu (oseltamivir), Relenza (zanamivir). Available at: http://www.emea.europa. eu/docs/en_GB/document_library/Other/2009/12/ WC500018446.pdf. Last accessed September 1, 2010.

150. Donner B, Niranhan V, Hoffmann G. Safety of oseltamivir in pregnancy: a review of preclinical and clinical data. Drug Saf. 2010;33:631-642.

151. Greer LG, Sheffield JS, Rogers VL, et al. Maternal and neonatal outcomes after antepartum treatment of influenza with antiviral medications. Obstet Gynecol. 2010;115:711-716.

152. Vu D, Peck AJ, Nichols WG, et al. Safety and tolerability of oseltamivir prophylaxis in hematopoietic stem cell transplant recipients: a retrospective case-control study. Clin Infect Dis. 2007;45:187-193.

153. Ison MG, Szakaly P, Shapira MY, et al. Oseltamivir prophylaxis reduces the occurrence of influenza infection in transplant recipients. 14th Annual Congress of the European Society for Organ Transplantation. Paris, France. August 30-September 2, 2009. Abstract.

154. Redelman-Sidi G. Influenza in patients with hematologic disease: an ounce of prevention is worth a pound of cure. Leuk Lymphoma. 2010;51:1954-1956.
155. Watcharananan SP, Suwatanapongched T, Wacharawanichkul $\mathrm{P}$, et al. Influenza A/H1N1 2009 pneumonia in kidney transplant recipients: characteristics and outcomes following highdose oseltamivir exposure. Transpl Infect Dis. 2010;12:127-131.

156. Dutkowski R, Smith JR, Davies BE. Safety and pharmacokinetics of oseltamivir at standard and high dosages. Int $\mathrm{J}$ Antimicrob Agents. 2010;35:461-467.

157. Schmidt AC. Antiviral therapy for influenza : a clinical and economic comparative review. Drugs. 2004;64:2031-2046.

158. Lynd LD, Goeree R, O'Brien BJ. Antiviral agents for influenza: a comparison of cost-effectiveness data. Pharmacoeconomics. 2005;23:1083-1106.

159. Postma MJ, Beardsworth P, Wilschut JC. Cost effectiveness of oseltamivir treatment of influenza: a critique of published methods and outcomes. J Med Econ. 2008;11:743-768.

160. Sander B, Hayden FG, Gyldmark M, Garrison LP, Jr. Post-exposure influenza prophylaxis with oseltamivir: cost effectiveness and cost utility in families in the UK. Pharmacoeconomics. 2006;24:373-386.

161. Postma MJ, Novak A, Scheijbeler HW, et al. Cost effectiveness of oseltamivir treatment for patients with influenza-like illness who are at increased risk for serious complications of influenza: illustration for the Netherlands. Pharmacoeconomics. 2007;25:497-509.

162. Talbird SE, Brogan AJ, Winiarski AP, Sander B. Costeffectiveness of treating influenzalike illness with oseltamivir in the United States. Am J Health Syst Pharm. 2009;66:469-480.

163. Nagase H, Moriwaki K, Kamae M, Yanagisawa S, Kamae I. Cost-effectiveness analysis of oseltamivir for influenza treatment considering the virus emerging resistant to the drug in Japan. Value Health. 2009;12(Suppl. 3):S62-S65.

164. Lugner AK, Postma MJ. Mitigation of pandemic influenza: review of cost-effectiveness studies. Expert Rev Pharmacoecon Outcomes Res. 2009;9:547-558.

165. Sander B, Nizam A, Garrison Jr LP, et al. Economic evaluation of influenza pandemic mitigation strategies in the United States using a stochastic microsimulation transmission model. Value Health. 2009;12:226-233. 